\title{
导向基团辅助过渡金属催化间位碳氢官能化研究进展
}

\author{
吴 梅*, $a$ 黄新平 $b$ 张海兵 ${ }^{a}$ 李鹏飞 $a$ \\ ( ${ }^{a}$ 中国石油大学(北京)克拉玛依校区 重质油国家重点实验室 新疆克拉玛依 834000) \\ ${ }^{b}$ 中石油克拉玛依石化有限责任公司 新疆克拉玛依 834000)
}

\begin{abstract}
摘要 碳氢键活化是目前非常活跃的研究领域之一, 然而实现碳氢键位点选择性活化是该领域面临的挑战之一. 以辅 助基团作为导向基，实现碳氢键间位活化引起了众多学者的极大关注，经常采用的策略包括模板导向、降冰片烯介导 和配体的次级效应. 对近年来通过导向基团进行的间位碳氢键活化的研究进行了详细的综述, 总结了目前存在的问题, 并对今后的发展方向进行了展望.
\end{abstract}

关键词 模板导向; 间位活化; 碳氢官能化; 次级效应; 瞬时介导

\section{Advances on Directing-Group Assisted meta-C-H Functionalization Catalyzed by Transition Metal}

\author{
Wu, Mei ${ }^{*, a} \quad$ Huang, Xinping ${ }^{b} \quad$ Zhang, Haibing $^{a} \quad$ Li, Pengfei ${ }^{a}$ \\ $\left({ }^{a}\right.$ State Key Laboratory of Heavy Oil Processing, China University of Petroleum-Beijing At Karamay, \\ Karamay, Xingjiang 834000) \\ ( ${ }^{b}$ Petrochina Karamay Petrochemical CO. LTD, Karamay, Xingjiang 834000)
}

\begin{abstract}
Transition-metal-catalyzed functionalization of unactivated $\mathrm{C}-\mathrm{H}$ bonds is a highly attractive strategy for the synthesis of organic molecules, however, regioselective control is a central challenge in this field. The directing group assisted $\mathrm{C}-\mathrm{H}$ functionalizations such as the use of directing templates and transient mediator, secondary interaction have attracted more attentions from researchers. The meta-C-H functionalizatioin assisted by directing groups are summarized in details. The existing problems and limitations of this field are also included. Finally, the development trend of this area is prospected. Keywords directed by template; meta-activation; $\mathrm{C}-\mathrm{H}$ functionalization; secondary interaction; transient mediator
\end{abstract}

过渡金属催化的惰性碳氢键直接官能化是合成有 机分子的重要方法之一，被广泛应用于生物制药、农药、 食品和有机材料等领域, 是非常活跃的研究领域. 由于 一个分子中往往存在多个反应活性相近的碳氢键, 因此 位点选择性的进行碳氢活化是碳氢键活化面临的挑战 之一. 在过去的几年里, 间位碳氢键活化取得了一定的 进展, 一是通过位阻和电性来调节 ${ }^{[1 ~ 3]}$, 但这仅局限于 1,3-二取代的底物, 大大限制了反应底物. 二是通过导 向基来诱导 ${ }^{[4 \sim 7]}$, 常用的策略包括模板导向、降冰片烯 介导及配体次级效应等, 此种方法克服了底物中固有的 电子效应和空间效应, 扩大了底物的适用范围, 具有一 定的优势. 本文将对近几年导向基团诱导及过渡金属催 化的间位碳氢键活化进行详细综述, 从催化体系的特
点、碳氢键活化的关键中间体中导向基团的构象及底物 的构象对反应的区域选择性的影响进行了探讨.

\section{1 模板导向间位官能化反应}

自 2012 年 $Y u$ 课题组 ${ }^{[8]}$ 报道了含有氰基导向基的模 板，实现了导向基定位的间位烯烃化，模板导向过渡金 属催化的远程碳氢键活化取得了一定的进展, 主要以氰 基和氮杂环为导向基，以 $\mathrm{U}$ 型模板(图 1)实现了甲苯、 酚、芐醇、苯基取代乙酸、3-苯丙酸、氢化喹啉和苯胺 等衍生物中苯环间位的碳氢官能化. 该策略通过模板构 象、底物构象以及活化 $\mathrm{C}-\mathrm{H}$ 与导向基团的相对位置的 控制，使催化剂接近间位 $\mathrm{C}-\mathrm{H}$, 来实现间位的选择性 活化(图 1), 导向基团距离间位 $\mathrm{C}-\mathrm{H}$ 一般 10 12 个原

* Corresponding author. E-mail: wumei_1121@163.com

Received March 15, 2019; revised May 31, 2019; published online June 19, 2019.

Project supported by the Science Foundation of China University of Petroleum-Beijing at Karamay (No. RCYJ2016B-03-003).

中国石油大学(北京)克拉玛依校区科研启动(No. RCYJ2016B-03-003)资助项目. 
子, 模板和底物的几何结构要使配位后的金属催化剂接 近活化位置.

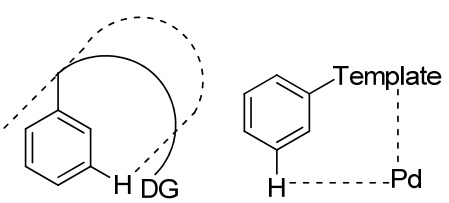

图 $1 \mathrm{U}$ 型模板及模板导向间位活化过渡态

Figure $1 \mathrm{U}$ template and transition state of meta-C $-\mathrm{H}$ activation

\section{1 氭基模板导向间位碳氢键活化}

直线型的氰基模板可缓解间位官能团化过渡态的 大环张力, 氧基为导向基的模板主要有氰化苄、羟基苯 腈和氨基苯腈.

\subsection{1 萻化苄为模板的间位官能化反应}

2012 年, Yu 课题组 ${ }^{[8]}$ 在模板导向间位碳氢键活化领 域做出了开创性工作，首次以氰基为导向基实现了芐基 醚的间位烯烃化(Eq. 1), 该反应以 $\mathrm{Pd}(\mathrm{OPiv})_{2}$ 为催化剂、 $\mathrm{AgOPiv}$ 为氧化剂, 丙烯酸乙酯为烯烃化试剂, 以中等 到优秀产率得到间位取代的产物, 对各种化学性质的取 代基(吸电子和给电子)取代的单梄都有很好的区域选择 性，苯环上取代基的位置对反应的区域选择性影响不 大，但是对于苯环上无取代基或对位取代的底物会伴随 一定比例两个间位同时被取代的二取代产物. 对于烯烃 化试剂, 乙烯基乙基酮、丙烯酸酯和乙烯基膦酸二乙酯 都能与间甲基芐醚发生烯烃化反应，甚至一些二取代烯 烃和三取代的环状烯烃也能高活性、高选择性地生成间 位烯烃化和烯丙基化产物. 他们认为弱配位的直线型氰 基可使催化剂接近被活化的碳氢键，降低大环金属过渡 态的环张力, 促进碳氢键活化. 他们对苄基醚间位烯烃 化反应进行了机理研究 ${ }^{[9]}$, 认为反应过程经过脱质子碳 氢键活化、烯烃插入、 $\beta$-氢消除和还原消除四个步骤, 其 中碳氢键活化决定反应速率以及产物的区域选择性. $\operatorname{PdAg}(\mathrm{OAc})_{3}$ 是反应活性物种, 因为该活性物种活化邻、 间和对位碳氢键得到的大环过渡态分别是 14、15 和 16 元环, 更稳定(图 2). 银盐在反应中一是作为氧化剂, 二 是与导向基配位形成大环过渡态. 碳氢活化过渡态中 C-N-Ag 的角度以及二面角 $\Psi_{3}$ 对产物的区域选择性有很 大的影响, $\Psi_{3}$ 在底物中为 $174^{\circ}$, 在过渡态中 C-N-Ag 角 度和二面角 $\Psi_{3}$ 越接近 $180^{\circ}$ ( $\mathrm{Ph}$ 和 $\mathrm{Ar}$ 处于对位交叉式) 越稳定(图 2), 在碳氢活化步骤中, 活化邻、间和对位碳 氢键得到的大环过渡态中 $\Psi_{3}$ 分别为 $-166^{\circ},-173^{\circ}$ 和 $154^{\circ}$, 活化间位的过渡态更接近底物的分子构象, 底物 不易变形, C-N-Ag 的角度分别为 $160^{\circ}, 156^{\circ}$ 和 $135^{\circ}$, 此 外二面角 $\Psi_{4}$ 对产物的区域选择性也有影响作用, $\Psi_{4}$ 接
近 $0^{\circ}$, 过渡态稳定性变差, 在过渡态中在碳氢活化步骤 中活化邻位和间位得到的过渡态分别为 $1^{\circ}$ 和 $-44^{\circ}$, 因 此主要得到间位产物. 模板中 $t-\mathrm{Bu}$ 使模板的构象接近过 渡态的构象，对反应活性和选择性也起到了重要作用. 总之, 过渡态中底物的变形程度影响了反应的区域选择 性.

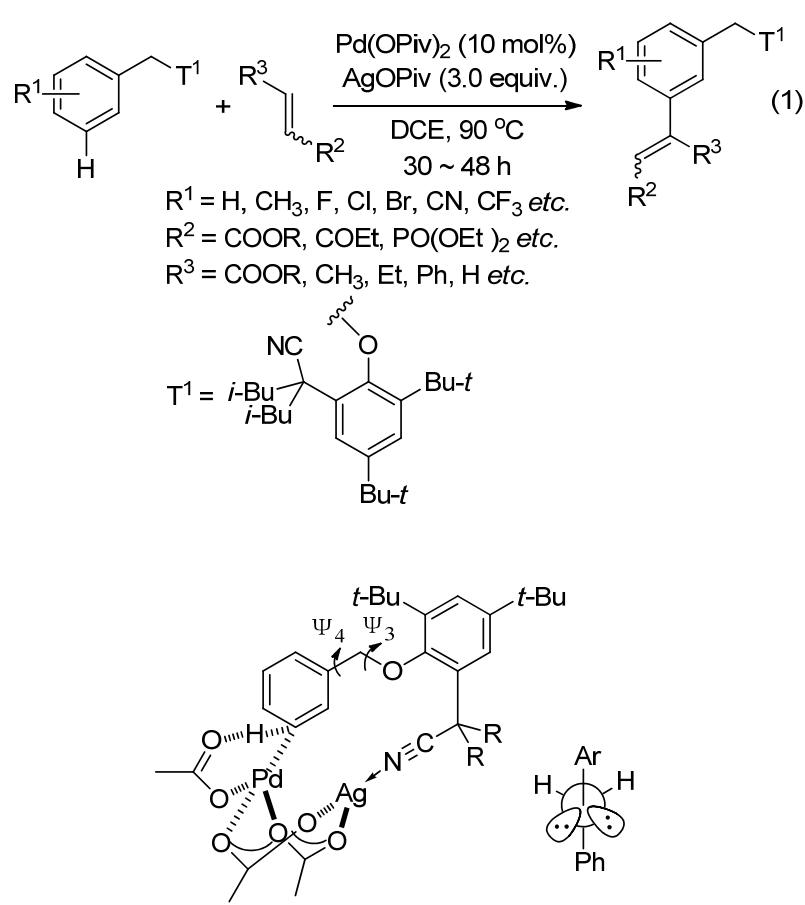

图 2 芳基醚间位碳氢活化过渡态和 $\Psi_{3}$

Figure 2 Transition state of benzyl ether derivatives of meta$\mathrm{C}-\mathrm{H}$ activation and $\Psi_{3}$

与此同时, Tan 课题组 ${ }^{[10]}$ 报道了以硅氧基连接氰基 模板与苄醇类衍生物, $\mathrm{Pd}(\mathrm{OAc})_{2}$ 催化茮醇间位烯烃化反 应(Eq. 2)，该模板合成方法简单，容易与茮醇反应，而 且容易脱除，在考察范围内，各种取代茮醇有很好的间 位选择性，但是邻位取代的底物会得到一定比例的二取 代产物，苯环上强吸电子的取代基导致烯烃化产物产率 降低，由于位阻效应，对位取代的芐醇间位选择性略有 降低；该体系对一系列缺电子的烯烃都有好的反应活性

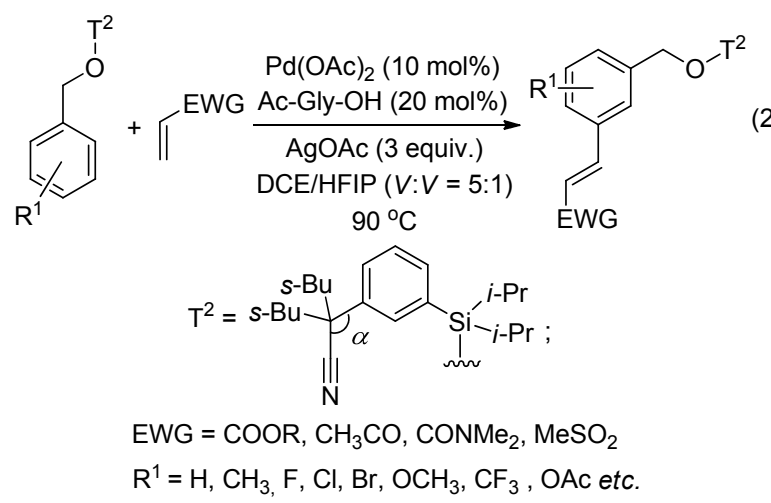


和选择性. 氰基与苯环之间的夹角 $\alpha$ 对区域选择性有很 大的影响，通过调整苄基位取代基可改变 $\alpha$, 当取代基 是 $s-\mathrm{Bu}$ 时，得到最好的间位选择性和最高产率.

由于氮原子的给电子效应, 二氢吲哚类化合物苯环 电子云密度增大，邻位和对位碳氢键更容易被活化，Yu 等 ${ }^{[11]}$ 以硫酰基连接氰化茮模板和二氢吲哚, $\mathrm{Pd}(\mathrm{OAc})_{2}$ 作 催化剂, 实现了二氢吲哚类化合物间位烯烃化(Eq. 3)、 芳基化(Eq. 4)和乙酰氧化(Eq. 5), 反应底物适用范围广 且选择性好, 以较高的选择性得到间位取代的产物. 硫 酰基能降低苯环邻位和对位电子云的密度, 使苯环的间 位容易活化. 另外, 可能由于模板茮基位偕二甲基效应 的存在, 模板中氰基 $\alpha$ 位偕二烷基的引入可以调整模板 的构象, 使模板的构象更接近间位活化过渡态的构象, 有利于导向基辅助间位碳氢键的活化.
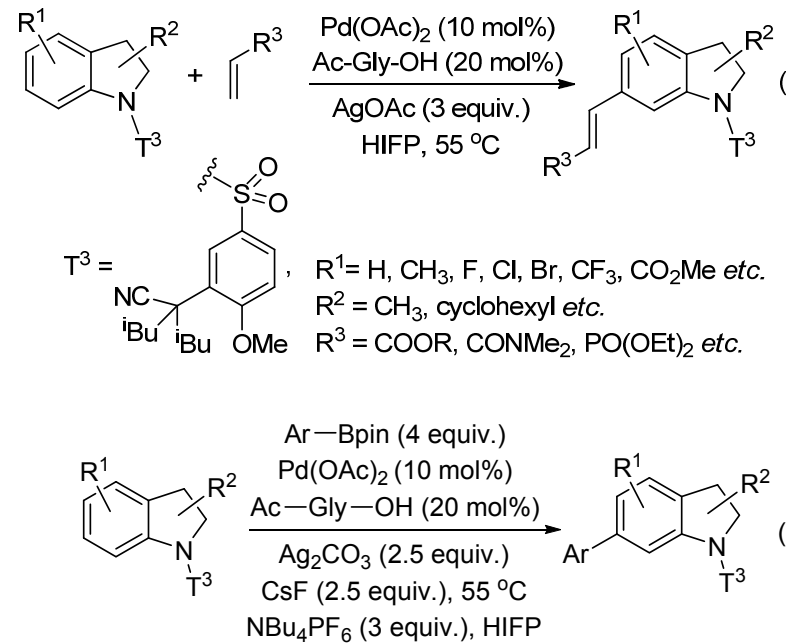<smiles>COc1ccc(S(C)(=O)=O)cc1C(C)(C)C(C)(C)C</smiles>

$\mathrm{R}^{1}=\mathrm{H}$ $\mathrm{R}^{2}=\mathrm{CH}_{3}, \square, \square$, etc.

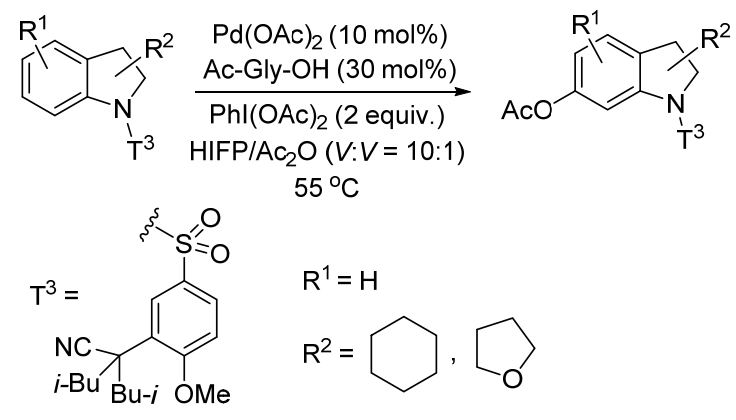

2017 年, Zhou 等 ${ }^{[12]}$ 以硅氧键连接氰化苄模板和苯 酚，实现了苯酚及其衍生物间位烯烃化反应(Eq. 6), 该 体系底物适用范围广，对一系列的烯烃及苯酚衍生物都 有很高的催化活性和间位选择性. 2018 年, 该小组 ${ }^{[13]}$ 又 将此氰基模板应用于 $\mathrm{Rh}$ 催化的苯酚衍生物间位烯烃化
反应中(Eq. 7), 该体系底物适用范围广, 对一系列的烯 烃及苯酚衍生物都有很高的催化活性和间位选择性. 当 苯酚含有一个取代基时，无论取代基在苯环上的位置还 是取代基的空间效应如何，都能高选择性得到间位产 物，丙烯酸酯、丙烯腈、乙烯基膦酸酯、丙烯醛和苯基 乙烯基砜都可与苯酚反应，高选择性得到间位取代产 物.

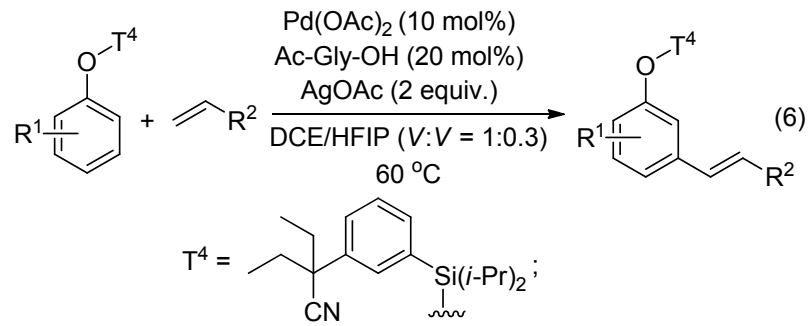
$\mathrm{R}^{1}=\mathrm{H}, \mathrm{CH}_{3}, \mathrm{~F}, \mathrm{Cl}, \mathrm{Br}, \mathrm{OCH}_{3}, \mathrm{CO}_{2} \mathrm{Me}, \mathrm{CF}_{3}$ etc. $\mathrm{R}^{2}=\mathrm{COOR}, \mathrm{CHO}, \mathrm{PO}(\mathrm{OEt})_{2}, \mathrm{SO}_{2} \mathrm{Ph}, \mathrm{CN}$

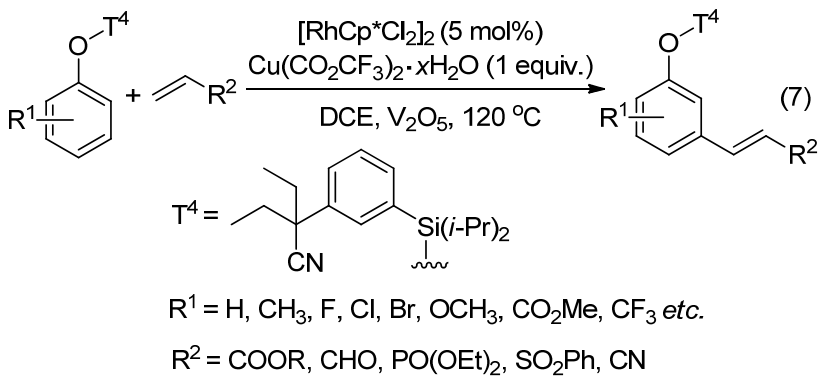

\subsection{2 氨基苯腈为模板的间位官能化反应}

$\mathrm{Yu}$ 小组 ${ }^{[8]}$ 将氨基苯腈模板 $\mathrm{T}^{5}$ 应用于 3 -苯基丙酸及 其衍生物间位烯烃化反应中，反应以 $N$-乙酰基甘氨酸 为配体, 得到了很好的结果(Eq. 8). Houk 等 ${ }^{[14]}$ 对 $N$-乙酰 基甘氨酸配体在反应中的作用进行了研究，认为碳氢键 活化决定反应速率以及产物的区域选择性, $\mathrm{Pd}(\mathrm{OAc})_{2} \mathrm{~L}$ 是反应的活性物种, 氨基酸配体既能稳定钯催化剂, 又 能作为碱, 在碳氢活化步骤脱除苯环中的氢. $\alpha_{1}(\mathrm{Pd} 1-\mathrm{C} 2-\mathrm{O} 3-\mathrm{C} 4)$ 影响产物的区域选择性, $\alpha_{1}=0$ 时, 四
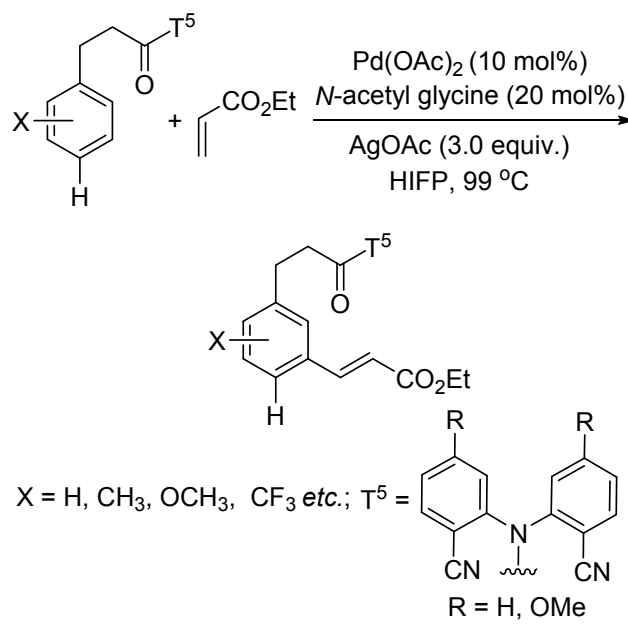
个原子在同一个平面上, 有利于氢原子的脱除. 底物中 苯环与 Pd1-C2-O3-C4 所在平面的夹角 $\alpha_{2}$ 对产物的区域 选择性也有影响作用, 两个平面垂直对反应有利, 当烯 烃化分别发生在邻、间和对位时 $\alpha_{1}$ 和 $\alpha_{2}$ 分别为 $17^{\circ} 、 81^{\circ}$ 、 $0^{\circ}$ 和 $88^{\circ} 、-6^{\circ}$ 和 $84^{\circ}$. 此外, O5 $=\mathrm{C} 6-\mathrm{C} 7-\mathrm{C} 8$ 顺式共平面 对反应有利 (二面角 $\alpha_{3}=0$ ), 在反应物中 $\alpha_{3}=-7^{\circ}$, 在 邻、间和对位取代的过渡态中, $\alpha_{3}$ 分别是 $-60^{\circ} 、-27^{\circ}$ 和 $-42^{\circ}$ (图 3), 也就是说活化间位底物的变形程度小. 综合以上因素, 过渡态的变形程度和模板的变形程度决 定了产物的区域选择性.

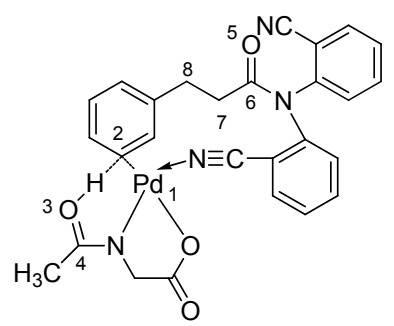

图 3 3-苯基丙酸间位碳氢活化过渡态

Figure 3 meta-C-H activation transition state of 3-phenylpropanoic acid derivatives

随后， $\mathrm{Yu}$ 等 ${ }^{[15]}$ 又将 $\mathrm{T}^{5}$ 模板应用到富电子苯酚类衍 生物的间位烯烃化反应中 (Eq. 9), 该反应以 $\mathrm{Pd}(\mathrm{OAc})_{2}$ 为 催化剂、 $\mathrm{AgOAc}$ 为氧化剂、六氟异丙醇(HIFP)作溶剂, 并加入一定量的配体, 此反应体系的底物适用范围广, 选择性好, 与苯酚环上的各种电子效应的取代基都有很 好的兼容性; $\alpha, \beta$-不饱和羧酸酯、膦酸酯、酰胺以及苯环 上含有吸电子取代基的苯乙烯都可作为烯烃化试剂发 生烯烃化反应.

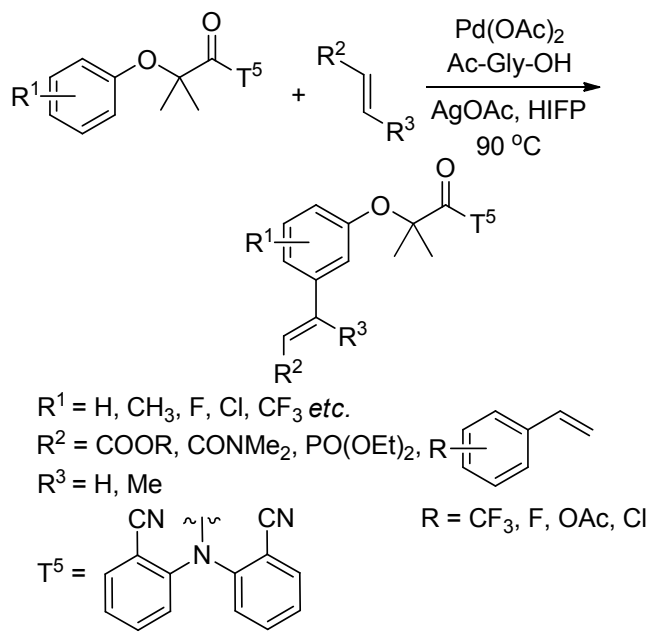

$\mathrm{Yu}$ 等 ${ }^{[16]}$ 以 $\mathrm{T}^{5}$ 为模板首次实现 3-苯基丙酸和苯酚及 其衍生物的芳基化反应, 反应以 $\mathrm{Pd}(\mathrm{OAc})_{2}$ 为催化剂、碳 酸银为氧化剂、Ac-Gly-OH 为配体、 $\mathrm{CsF}$ 和四丁基六氟 磷酸铵 $\left(\mathrm{TBAPF}_{6}\right)$ 分别为碱和添加物, 芳基硼酸作芳基
化试剂(Scheme 1), 以 42\% 85\%产率得到芳基化产物, 各种一取代的 3-苯基丙酸衍生物都高选择性地得到间 位芳基化产物，但是由于位阻效应，二取代 3-苯基丙酸 衍生物基本不发生反应，该反应体系为合成芳基取代的 3-苯基丙酸和酚衍生物提供了新的合成方法.
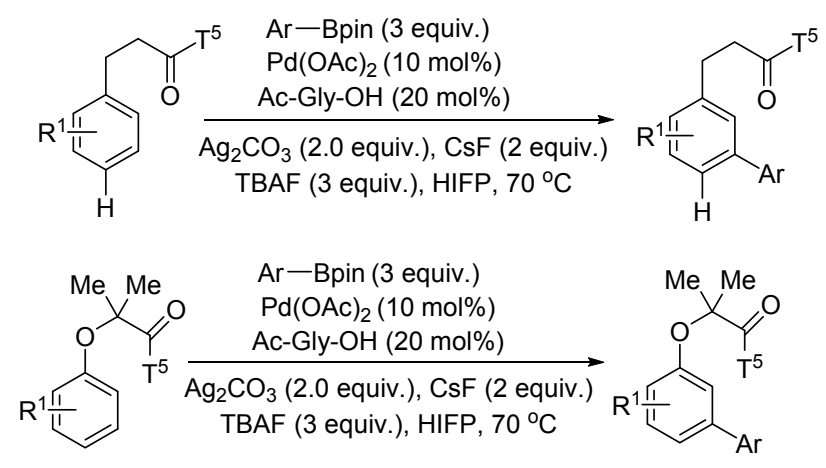

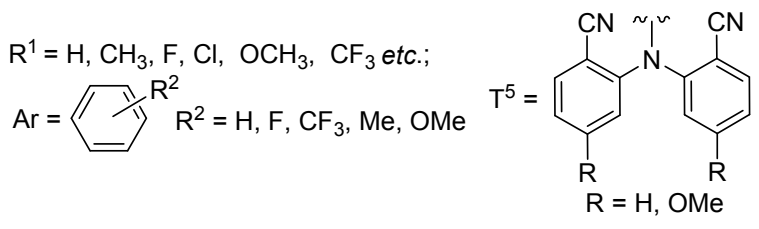

图式 1 苯酚和 3-苯基丙酸间位芳基化反应 Scheme 1 Meta-arylation of 3-phenylpropanoic acid and phenolic derivatives

随后, $\mathrm{Yu}$ 等 ${ }^{[17]}$ 又将模板 $\mathrm{T}^{5}$ 应用于 $\mathrm{Pd}(\mathrm{OAc})_{2}$ 催化苯 乙酸衍生物间位的烯烃化反应(Eq. 10), 该反应适用范 围广，考察范围内的各种单取代苯乙酸、 $\alpha$-甲基取代苯 乙酸都能与丙烯酸乙酯发生反应, 高选择性地得到间位 取代产物, 但是对位取代的苯乙酸间位烯烃化产率要低 一些，而溴代和碘代苯乙酸不能发生反应，二取代苯乙 酸也能高选择性地得到间位烯烃化产物; 甲基乙烯基 酮、 $N, N$-二甲基丙烯酰胺、乙烯基膦酸二乙酯和丙烯醛 都能与间甲基苯乙酸发生反应, 高产率和高选择性地得 到间位烯烃化产物, 配体和 $\mathrm{KH}_{2} \mathrm{PO}_{4}$ 对反应至关重要.

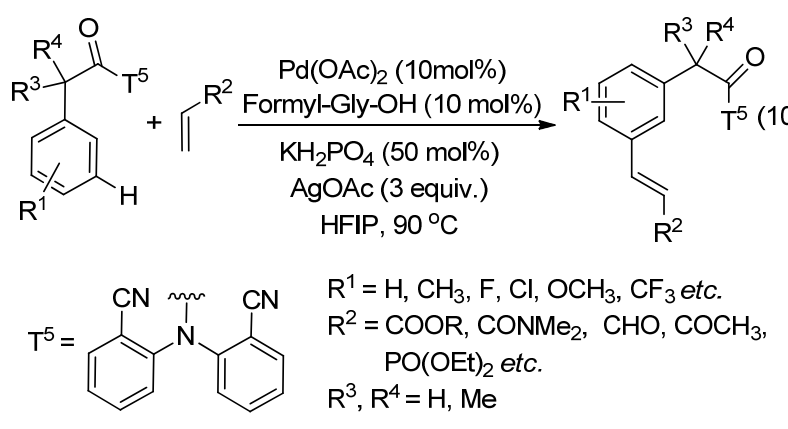

$\mathrm{Rh}$ 催化剂在邻位碳氢官能化反应中有很高的活性. 2017 年, $\mathrm{Yu}$ 课题组 ${ }^{[18]}$ 首次报道了 $\left[\mathrm{RhCp}^{*} \mathrm{Cl}_{2}\right]_{2}$ 催化 3-苯 基丙酸衍生物间位烯烃化反应(Eq. 11), 该反应以氨基 苯腈 $\mathrm{T}^{6}$ 为模板、 $\mathrm{Cu}\left(\mathrm{CO}_{2} \mathrm{CF}_{3}\right)_{2} \cdot x \mathrm{H}_{2} \mathrm{O}$ 为氧化剂、 $\mathrm{CF}_{3} \mathrm{COOH}$ 
作添加剂. 在考察的底物范围内, 各种取代的 1-苯基丙 酸都有很高的间位选择性, 而且没有间位二取代产物生 成, 但是该反应对 1-苯基丙酸对位取代基的电子效应和 位阻效应敏感，当取代基是 4- $\mathrm{NO}_{2}$ 或 4- ${ }^{t} \mathrm{Bu}$ 时，反应基本 不发生. 催化体系对于烯烃底物适用范围广, 丙烯酸 酯、 $N, N$-二甲基丙烯酰胺、乙基乙烯基酮、丙烯酫、 $\beta$ 取代烯酮、乙烯基二乙基膦酸酯、苯基乙烯基砜以及苯 环上含有吸电子取代基的苯乙烯都能高产率地得到烯 烃化产物. 最近, Yu 课题组 ${ }^{[19]}$ 又将该模板应用到以二取 代炔烃为烯烃化试剂的 1-苯基丙酸间位烯烃化反应中 (Eq. 12), 反应以 $\left[\mathrm{RhCp}^{*} \mathrm{Cl}_{2}\right]_{2}$ 为催化剂, 当底物是邻、 间、对位一取代的 1-苯基丙酸衍生物时都只得到间位一 取代产物, 炔丙基醇也能很好地发生烯烃化反应, 此反 应为合成间烯基取代 3-苯丙酸提供了一种方法. 这是 $\mathrm{Rh}$ 催化炔烃与 1-苯基丙酸间位烯烃化的首例报道.<smiles>O=C([IH])CCc1[R1]ccc1</smiles>

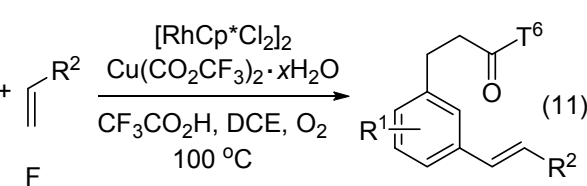<smiles>CCN(c1ccccc1F)c1ccccc1C#N</smiles>
$\mathrm{R}^{1}=\mathrm{H}, \mathrm{CH}_{3}, \mathrm{~F}, \mathrm{Cl}, \mathrm{Br}, \mathrm{OCH}_{3}, \mathrm{CF}_{3}$ etc. $\mathrm{R}^{2}=\mathrm{COOR}, \mathrm{CONMe}_{2}, \mathrm{PO}(\mathrm{OEt})_{2}, \mathrm{C}_{6} \mathrm{H}_{4} \mathrm{~F}$<smiles>[R]C#CCCCC(=O)CCc1[R1]cccc1</smiles>
$\left[\mathrm{RhCp}{ }^{*} \mathrm{Cl}_{2}\right]_{2}$ $\underset{\mathrm{DCE}, 120^{\circ} \mathrm{C}}{\mathrm{AgSbF}_{6}, \mathrm{Ag}_{3} \mathrm{PO}_{4}}$
$\mathrm{CH}_{2} \mathrm{CH}_{2} \mathrm{COOH}$
$\mathrm{D}$<smiles>[Y]/C=C\C([R])=C1C=[R1]=C(CCC(=O)O)C1</smiles><smiles>C=CN(c1ccccc1N)c1ccccc1F</smiles>

$\mathrm{R}^{1}=\mathrm{H}, \mathrm{CH}_{3}, \mathrm{~F}, \mathrm{Cl}, \mathrm{Br}, \mathrm{OCH}_{3}, \mathrm{CF}_{3}$ etc. $\mathrm{R}^{2}=\mathrm{CH}_{3}, p-\mathrm{MeC}_{6} \mathrm{H}_{4}, p-\mathrm{FC}_{6} \mathrm{H}_{4}$, $p-\mathrm{BrC}_{6} \mathrm{H}_{4}, \mathrm{Et}, n-\mathrm{Pr}$ etc. $\mathrm{Ar}=p-\mathrm{ClC}_{6} \mathrm{H}_{4}, p-\mathrm{CNC}_{6} \mathrm{H}_{4}, p-\mathrm{BrC}_{6} \mathrm{H}_{4}$, $p-\mathrm{FC}_{6} \mathrm{H}_{4}, p-\mathrm{CH}_{3} \mathrm{C}_{6} \mathrm{H}_{4}$ etc.

\subsection{3 羟基苯腈为模板的间位官能化反应}

羟基苯腈可直接购买得到, 不需要合成, 作为模板 与底物容易反应, 且结构简单, 反应后模板易于脱除.

2014 年, Maiti 等 ${ }^{[20]}$ 以 2-羟基苯腈或 2-羟基-5-甲氧 基苯腈为模板, 以羰基连接模板和底物苯乙酸, 实现了 苯乙酸及其衍生物间位烯烃化, 反应以 $\mathrm{Pd}(\mathrm{OAc})_{2}$ 为催 化剂, $\mathrm{Ag}_{2} \mathrm{CO}_{3}$ 为氧化剂, 该反应体系能够容忍多种邻、 间、对位的取代基, 对于各种取代的苯乙酸都能以中等 到良好的产率得到间位选择性产物(Eq. 13), 但是该模 板对取代苯乙酸间位乙酰氧化和芳基化基本没有作用, 而且对于间位烯烃化产物会与溶剂发生酯交换反应.

硫酰基有强的吸电子效应, 能降低芐磺酸酯邻位和 对位电子云密度, 与羰基相比硫酰基可自由旋转, 能增 强氰基的导向能力, 而且硫酰基可转化为多种官能团. 2015 年, Maiti 等 ${ }^{[21]}$ 以 2-羟基苯腈为模板, 以硫酰基连接

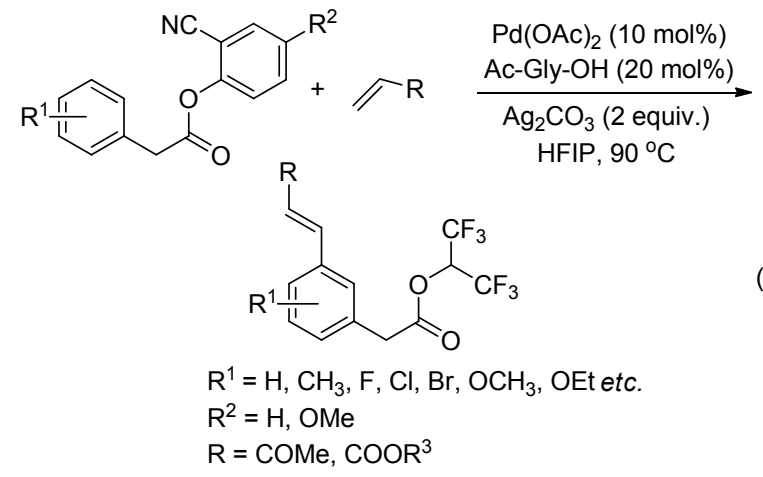

底物与模板, $\mathrm{Pd}(\mathrm{OAc})_{2}$ 为催化剂, $\mathrm{AgOAc}$ 为氧化剂, Ac-Gly-OH 为配体, 在优化的条件下实现了芐磺酸间位 的烯烃化, 在考察范围内苯环上分别含有吸电子和给电 子的邻、间、对取代基时都有很好的间位选择性. 烯烃 可以是 $\alpha, \beta$-不饱和酮、醛、羧酸酯、膦酸酯、磺酸酯和 酰胺等, 在优化的条件下, 二取代反式烯烃作为烯烃化 试剂主要得到 $E$ 构型产物, 甲基丙烯酸甲酯和环状三取 代烯烃得到间位烯丙基取代芐磺酸. 间位一取代产物可 以继续与不同的烯烃反应，得到两个间位同时被不同取 代基取代的产物. 当增加反应体系中烯烃的量时，可得 到两个间位同时被相同取代基取代的产物，二烃基取代 的芐磺酸酯脱除模板后得到三取代烯烃, 为合成 1,3,5三取代烯烃提供了一种重要的方法(Scheme 2). 随后, 他们 ${ }^{[22]}$ 改变反应条件, 以 $\mathrm{Pd}(\mathrm{OAc})_{2}$ 为催化剂、For-Gly$\mathrm{OH}$ 为配体, 在 $\mathrm{PhI}(\mathrm{TFA})_{2}$ 的作用下, 得到了芐磺酯间位 羟基化的产物(Eq. 14). 当配体变为 Boc-Ala-OH 时, 在 $\mathrm{PhI}(\mathrm{OAc})_{2}$ 的作用下, 得到是间位乙酰氧化的产物(Eq. $15)$.

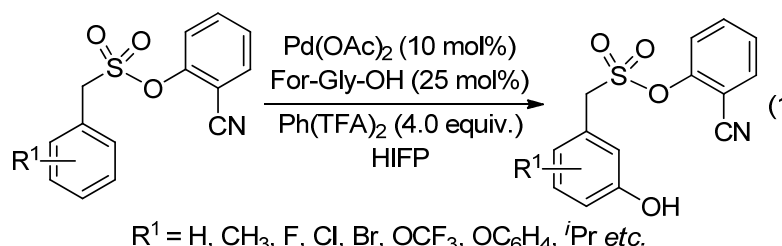

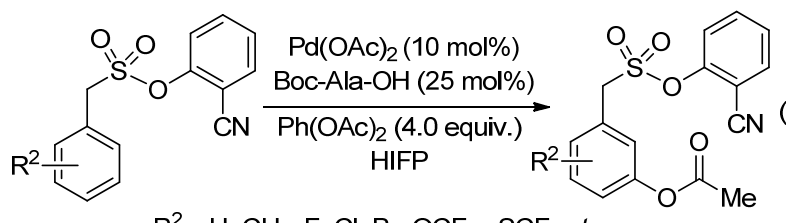

$\mathrm{R}^{2}=\mathrm{H}, \mathrm{CH}_{3}, \mathrm{~F}, \mathrm{Cl}, \mathrm{Br}, \mathrm{OCF}_{3}, \mathrm{SCF}_{3}$ etc.

Maiti 等 ${ }^{[23]}$ 还将 2-羟基苯腈模板应用到 2-苯基乙烷 磺酸和 3-苯基丙酸间位烯烃化反应中，高选择性地得到 间位产物. 得到的间位取代产物可以继续与烯烃发生反 应，得到间位带相同或不同取代基的二取代 2-苯基乙烷 磺酸以及 3-苯基丙酸(Scheme 3). 


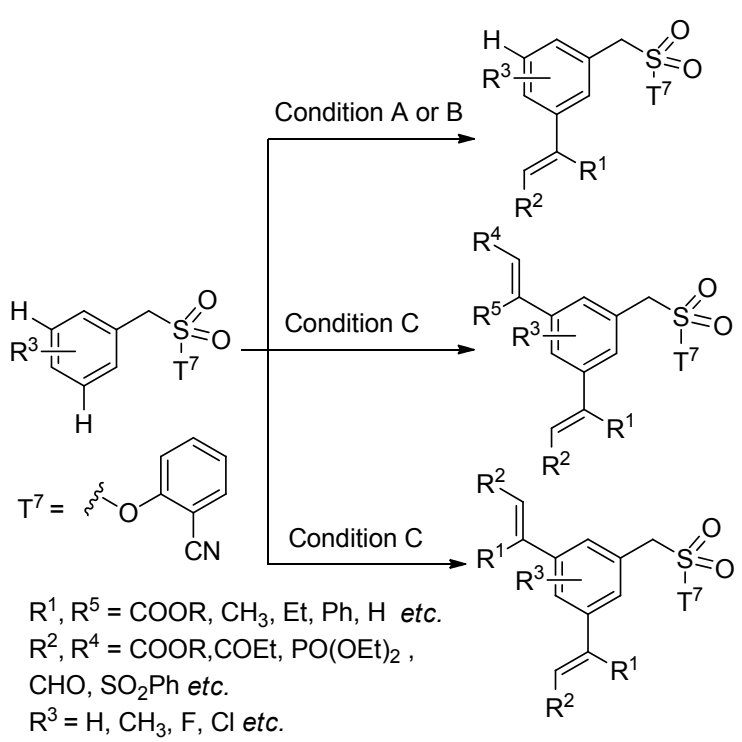

Condition A: Pd(OAc) 2 (10 mol\%), Ac-Gly-OH (20 mol\%), $\mathrm{Ag}_{2} \mathrm{CO}_{3}$ (1.5 equiv.), HIFP, DCE, $60{ }^{\circ} \mathrm{C}$; Condition B: $\mathrm{Pd}(\mathrm{OAc})_{2}(2 \mathrm{~mol} \%)$, Ac-Gly-OH (4 mol\%), $\mathrm{Ag}_{2} \mathrm{CO}_{3}$ (2.5 equiv.), HIFP, $80^{\circ} \mathrm{C}$; Condition C: $\mathrm{Pd}(\mathrm{OAc})_{2}(10 \mathrm{~mol} \%), \mathrm{Ac}-\mathrm{Gly}-\mathrm{OH}(20 \mathrm{~mol} \%), \mathrm{Ag}_{2} \mathrm{CO}_{3}$ (3 equiv.), HIFP, $80^{\circ} \mathrm{C}$

图式 2 苄磺酸酯间位烯烃化

Scheme 2 meta-Olefination of benzylsulfonyl ester derivatives

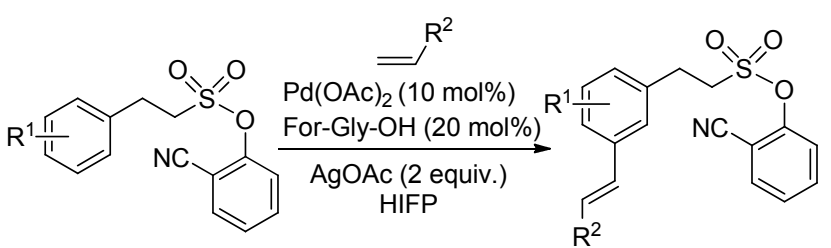

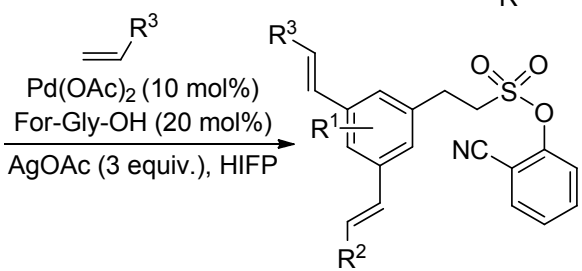

$\mathrm{R}^{1}=\mathrm{H}, \mathrm{F}, \mathrm{Cl}, \mathrm{Br}$ etc.

$\mathrm{R}^{2}, \mathrm{R}^{3}=\mathrm{COOR}, \mathrm{COR}, \mathrm{PO}(\mathrm{OEt})_{2}, \mathrm{CONMe}_{2}$

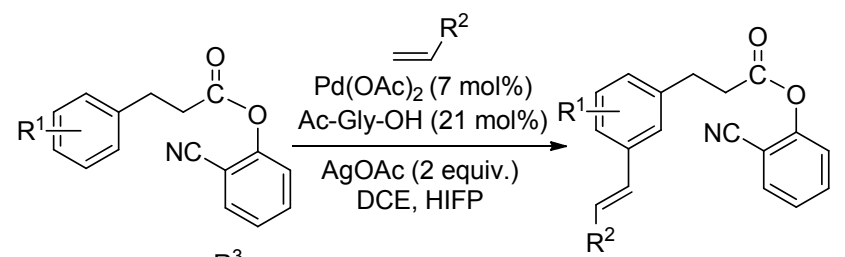

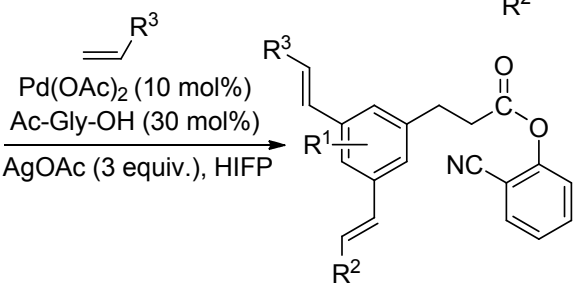

$\mathrm{R}^{1}=\mathrm{H}, \mathrm{F}, \mathrm{Cl}, \mathrm{Br}$ etc.

$\mathrm{R}^{2}, \mathrm{R}^{3}=\mathrm{COOR}, \mathrm{COR}, \mathrm{PO}(\mathrm{OEt})_{2}, \mathrm{CONMe}_{2}$

图式 32 -苯基乙磺酸和 3-苯基丙酸间位二烯烃化反应

Scheme 3 meta-Diolefination of 2-phenyl ethanesulfonic acid and 3-phenylpropanoic acid derivatives
2017 年, Maiti 等 ${ }^{[24]}$ 以 2-羟基-4-甲氧基苯腈为模板, 实现了茮磺酸(Eq. 16)和苯乙酸(Eq. 17)间位烯烃化，该 反应以 $\left[\{\mathrm{Rh}(\mathrm{COD}) \mathrm{Cl}\}_{2}\right]$ 为催化剂, $\mathrm{XPhos}$ 为配体, $\mathrm{V}_{2} \mathrm{O}_{5}$ 为 氧化剂, $\mathrm{Cu}\left(\mathrm{CO}_{2} \mathrm{CF}_{3}\right)_{2}$ 作共氧化剂, 共氧化剂对反应起到 了重要作用，吸电子和供电子取代基的邻、间、对位苄 磺酸都有很好的间位选择性和反应活性，位阻对该反应 活性略有影响，当苯磺酸对位被甲基取代时，间位产物 的产率是 $49 \%$; 烯烃可以是 $\alpha, \beta$-不饱和酮、 $\alpha, \beta$-不饱和 羧酸酯、乙烯基砜、丙烯醛和甲基乙烯基酮等. 他们对 反应机理进行了研究, 认为反应也是经过脱质子碳氢键 活化、烯烃插入、 $\beta$-氢消除和还原消除四个步骤.
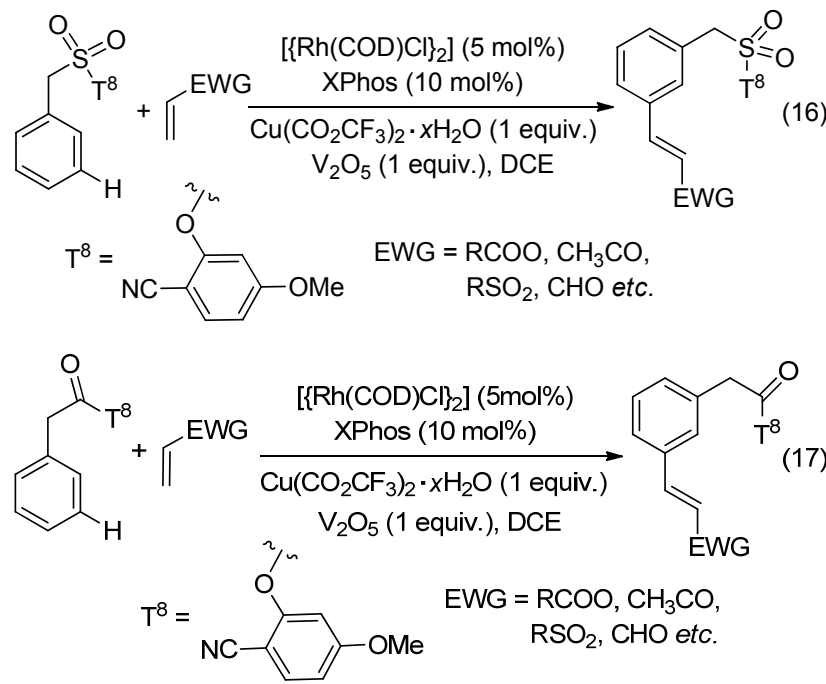

同年, Maiti 课题组 ${ }^{[25]}$ 首次报道了氰基模板导向钯 催化的茮磺酸酯类衍生物间位的硅烷化(Eq. 18)和硒烷 化(Eq. 19)反应, $\mathrm{CH}_{3}, \mathrm{~F}, \mathrm{Cl}$ 和 $\mathrm{CF}_{3}$ 取代的苄磺酸、二氟代 和三氟代茮磺酸以中等到良好产率和较高的选择性得 到间位硅烷化产物, 2-苯基乙烷磺酸和 3-苯基-1-丙烷磺 酸同样可以发生硅烷化反应.
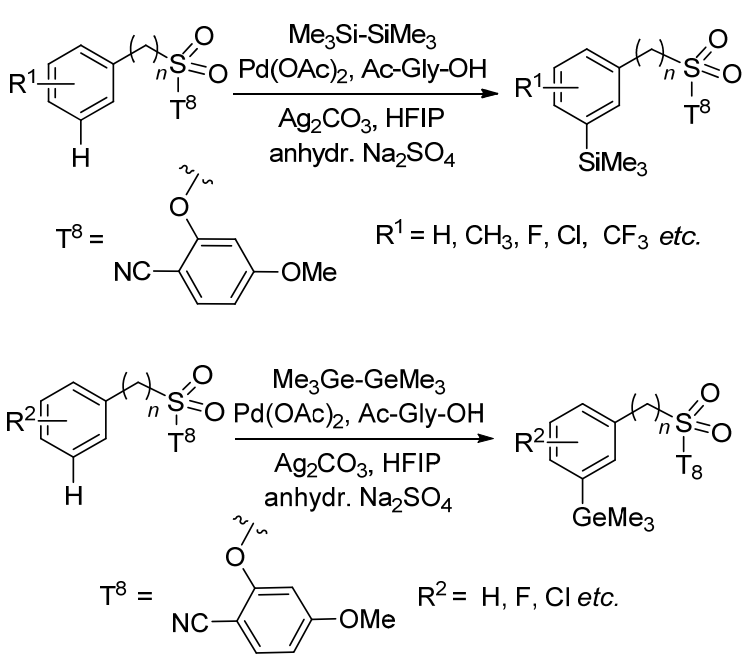

2016 年, Maiti 等 ${ }^{[26]}$ 报道了 2-氰基苯酚导向的苄基 
膦酸酯间位的烯烃化反应(Eq. 20), 这是关于此类反应 可在室温下进行的首例报道, 在优化的条件下, $\mathrm{Br}$ 和 $\mathrm{CH}_{3}$ 邻位或间位取代的茮基磷酸酯都高产率地得到间位 取代产物, 当对位取代基为 $\mathrm{Br}, \mathrm{CH}_{3}, \mathrm{OCH}_{3}$ 和 $\mathrm{Cl}$ 时同样 得到间位烯烃化产物, 但对位叔丁基取代芐基膦酸酯只 得到了 $15 \%$ 间位烯烃化产物.乙烯基膦酸酯、丙烯酸酯、 烯酮、乙烯基砜及苯环上含有乙酰基和硝基的苯乙烯都 可作为烯烃化试剂. 当改变反应体系中加入的配体, 并 提高反应体系的温度时，可得到间位相同或不同取代基 的二取代膦酸酯. 间位二取代膦酸酯脱去模板后可得到 1,3,5-三烃基取代的芳香化合物. 当用 $\mathrm{PhI}(\mathrm{OAc})_{2}$ 或 $\mathrm{PhI}(\mathrm{TFA})_{2}$ 代替烯烃时可得到间位乙酰氧化(Eq. 21)或羟 基取代(Eq. 22)的产物. 反应后的产物膦酸酯容易脱除 模板.

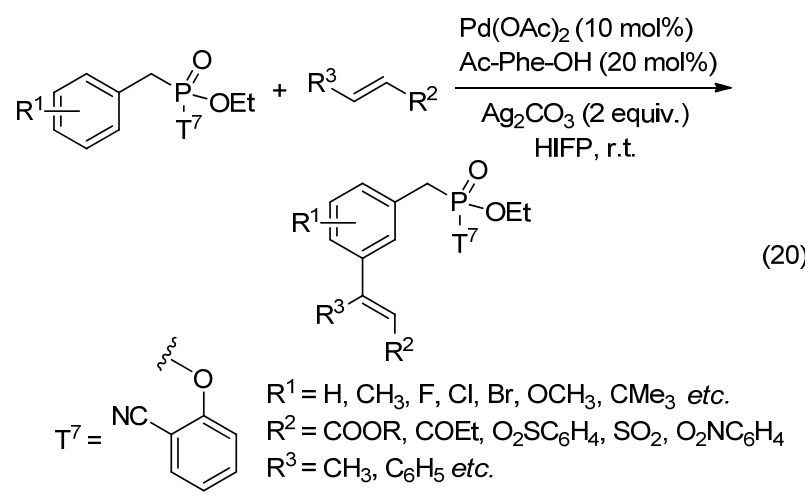

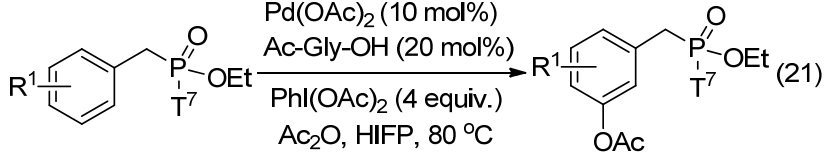<smiles>CCOc1ccccc1C#N</smiles><smiles>[R]=CCC([Ge]Br)[Se][Te]</smiles><smiles>[R7]COc1ccccc1C#N</smiles>

2016 年, Maiti 课题组 ${ }^{[27]}$ 报道了㲵基模板导向苄基 硅烷间位烯烃化反应，在考察范围内该催化体系对各种 取代苄基硅烷和烯烃都有良好的兼容性，高选择性地得 到间位取代产物，间位一取代产物可继续发生间位烯烃 化，从而得到间位二取代产物。间位一取代茮基硅烷可 以先脱除模板，再发生邻位烯烃取代反应，得到 2,5-二 烃基取代产物，也可以继续发生间位烯烃化反应，再脱 除模板，从而得到 3,5-二烃基取代产物(Scheme 4). 在脱 除模板的反应中可采取不同的反应条件，从而得到甲 苯、苯甲醛和苄醇等产物。
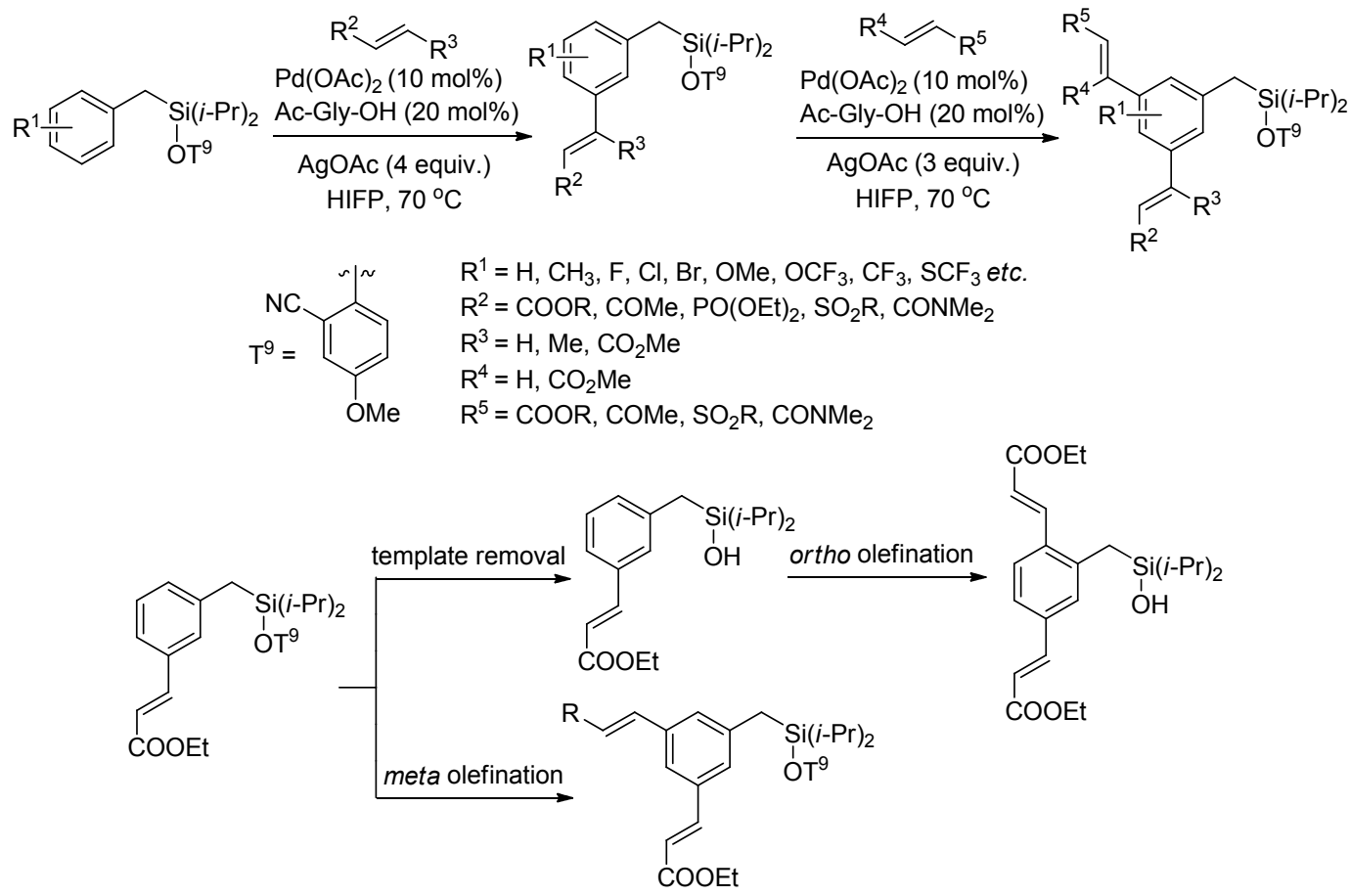

图式 4 苄基硅烷间位烯烃化反应

Scheme 4 meta-Olefination of benzyl silane derivatives 
2016 年, Maiti 等 ${ }^{[28]}$ 以羰基连接 2 -羟基苯腈模板和 二苯基羧酸以及二苯基酚及其衍生物, 实现了 $\mathrm{Pd}(\mathrm{OAc})_{2}$ 催化二苯基羧酸和二苯基酚及其衍生物间位 烯烃化反应(Scheme 5), 丙烯酸酯、乙烯基酮、乙烯基 膦酸酯、乙烯基砜、 $\beta$-取代丙烯醛以及丁烯酸二甲酯都 可以作为烯烃化试剂. $\mathrm{CH}_{3}$ 和 $\mathrm{Cl}$ 取代的二苯基乙酸与催 化体系有好的兼容性, 而 $\mathrm{OMe}$ 和 $\mathrm{OPh}$ 会使反应的选择 性大大降低, 杂环及䒺环底物不能发生反应.
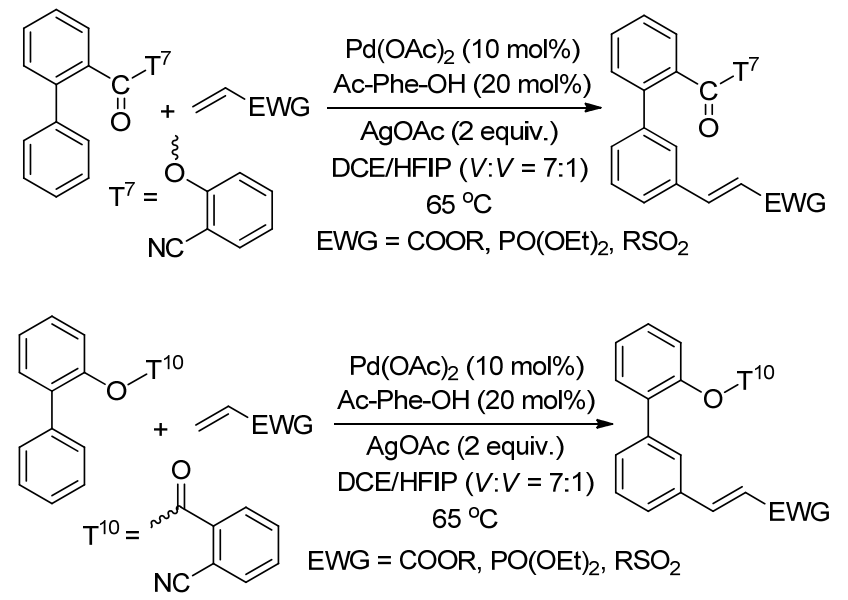

图式 5 二苯基羧酸和二苯基酚间位烯烃化 Scheme 5 Meta-olefination of biphenyl phenol and biphenyl carboxylic acid derivatives

2017 年, Xu 课题组 ${ }^{[29]}$ 报道了 2-羟基-5-甲氧基苯腈 模板导向的 2-苯乙醇、3-苯丙醇以及具有相似结构长链 同系物的苯环间位碳氢键的烯烃化 (Eq. 23), 反应以 $\operatorname{Pd}(\mathrm{OAc})_{2}$ 为催化剂, $\mathrm{AgOAc}$ 为氧化剂, 催化体系的活性 高, 底物适用范围广, 区域选择性好, 产物中二取代烯 烃的比例低, 不同碳原子数的醇和酚氧基醚等化合物都 可以与丙烯酸乙酯发生反应, 以较高的选择性得到间位 烯烃化产物. 作为烯烃化试剂, $N, N$-二甲基丙烯酰胺、苯 基乙烯基砜和 4-氟代苯乙烯等都可以与 3-苯丙醇和间 位甲基取代的 3-苯丙醇发生反应, 得到间位取代产物. 在优化的条件下二肽衍生物(1-Phe-Ser 和 1-Phg-Ser)也能 发生间位烯烃化反应。通过机理研究, 他们认为 $\operatorname{Pd} \mathrm{Ag}(\mathrm{OAc})_{3}$ 是反应的活性物种, 当苯环上的链比较短 时, 大环过渡态中 C-N-Ag 之间的角度对间位选择性起 重要作用, 最优角度是 $180^{\circ}$, 与邻位和对位产物相比, 间位产物碳氢活化过渡态中此夹角接近 $180^{\circ}$. 当链比较 长时, 苯基醚键的邻位交叉构象导致的扭转张力也起到 了重要作用(图 4), 在碳氢活化过渡态中二面角 $\Psi$ 越接 近 $180^{\circ}$ 越稳定.

\subsection{4 其它氧基模板导向间位官能化反应}

2014 年, $\mathrm{Yu}$ 小组 ${ }^{[30]}$ 以 $\mathrm{T}^{12}$ 为模板, 氧基为导向基、 $\operatorname{Pd}(\mathrm{OAc})_{2}$ 为催化剂实现了四氢喹啉和苯并吗啉等化合

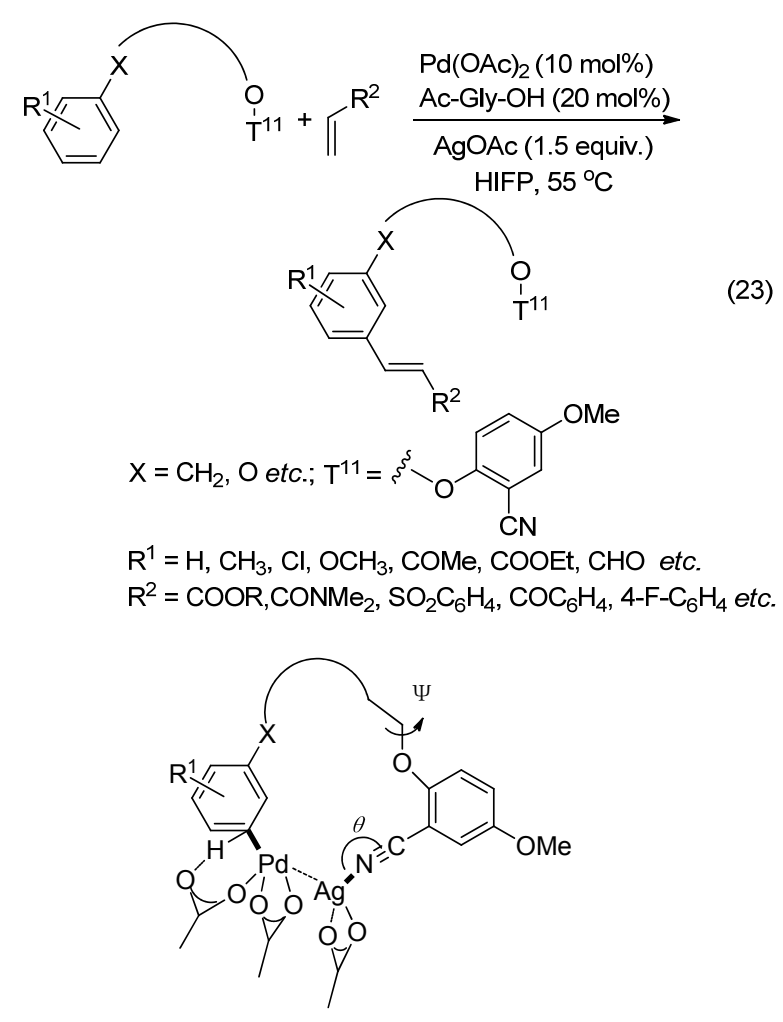

图 4 苯基醇间位活化过渡态

Figure 4 Transition state in meta-activation of phenyl alcohols 物及其衍生物 7-位碳氢键的烯烃化(Eq. 24). 模板中 F 的 电子效应对区域选择性影响不大, $\mathrm{F}$ 取代的模板的构象 对反应的区域选择性起到了重要的作用，由于 $\mathrm{F}$ 的存在, 模板中羰基远离 $\mathrm{C}(8)$ 位，从而避免 $\mathrm{C}(8)$ 位的烯烃化，有 利于-CN 导向活化 C(7), 从而得到间位产物. 他们还将 此模板应用到 $N$-甲基苯胺及芐胺类化合物间位的烯烃 化(Eq. 25)和乙酰氧化反应(Eq. 26)中，该反应体系对各 种化学性质的取代基都有良好的兼容性，但是苯环上无 取代基的底物二取代产物的比例略高于一取代产物.
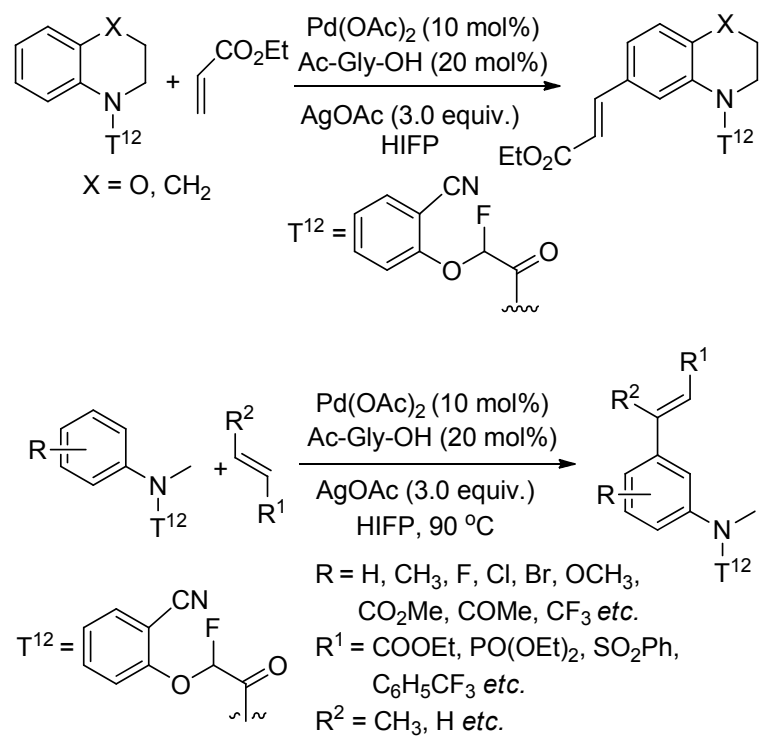


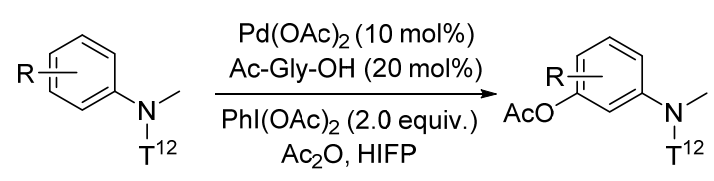<smiles>[Y]C(=O)C(F)Oc1ccc([Y7](=[Y])[H])cc1C#N</smiles>

2015 年, $\mathrm{Li}$ 小组 ${ }^{[31]}$ 报道了氰基导向 $\mathrm{Pd}(\mathrm{OAc})_{2}$ 催化 苯乙胺衍生物烯烃化反应(Eq. 27), 苯乙胺邻位和对位 含有给电子的 $\mathrm{CH}_{3}$ 和 $\mathrm{OCH}_{3}$ 以及吸电子的 $\mathrm{Br}$ 和 $\mathrm{Cl}$ 等取 代基时都可以高选择性地得到间位取代产物，但是对位 和邻位取代苯乙胺会生成间位二取代产物, 邻位取代苯 乙胺还会生成两个间位各自被取代的间位一取代产物, 组成较复杂. 模板中酰胺氮原子上的甲基对产物的选择 性至关重要，当酰胺氮原子上没有甲基取代基时得到的 是邻位烯烃化的产物.

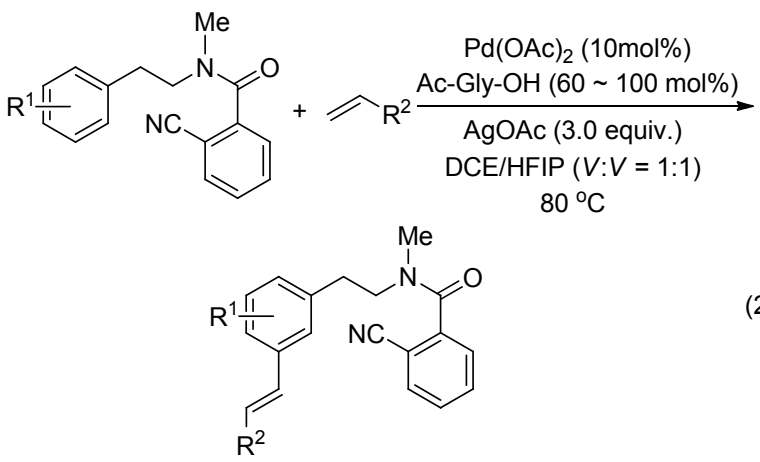

$\mathrm{R}^{1}=\mathrm{H}, \mathrm{CH}_{3}, \mathrm{~F}, \mathrm{Cl}, \mathrm{Br}, \mathrm{OCH}_{3}, \mathrm{CF}_{3}$ etc.

$\mathrm{R}^{2}=\mathrm{COOR}, \mathrm{CONMe}, \mathrm{COMe}, \mathrm{C}_{6} \mathrm{H}_{4} \mathrm{~F}, \mathrm{PO}(\mathrm{OEt})_{2}$

2016 年, $\mathrm{Li}$ 小组 ${ }^{[32]}$ 报道了模板 $\mathrm{T}^{13}$ 导向、 $\mathrm{Pd}(\mathrm{OAc})_{2}$ 催化的苯甲酸衍生物间位选择性烯烃化(Eq. 28)及乙酰 氧化反应(Eq. 29), 反应体系以氧气作氧化剂, 苯甲酸邻 位上给电子的取代基 $\mathrm{CH}_{3}$ 和 $\mathrm{OAc}$ 以及吸电子的取代基 $\mathrm{F}$ 和 $\mathrm{Cl}$ 时都可以高选择性得到间位产物, 但是空间位阻 小的 $\mathrm{F}, \mathrm{Cl}$ 和 $\mathrm{OAc}$ 主要得到间位二取代产物. 对位以及 间位取代基的电子效应和空间效应对选择性和产率基 本没有影响, 都以高产率和选择性得到间位一取代的产 物. 二取代以及三取代的苯甲酸都能高产率和选择性地

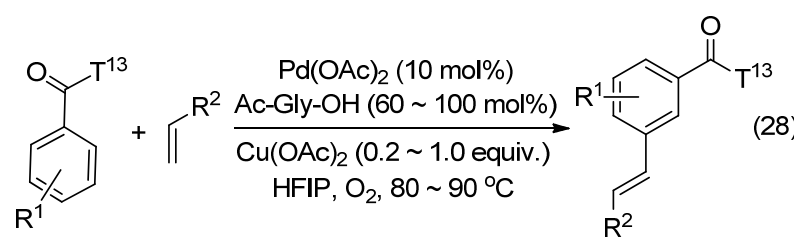<smiles>N#Cc1ccccc1CCN(C#N)[N+](=O)[O-]</smiles>

$\mathrm{R}^{1}=\mathrm{CH}_{3}, \mathrm{~F}, \mathrm{Cl}, \mathrm{Br}, \mathrm{OCH}_{3}, \mathrm{OAc}, \mathrm{H}$ etc. $\mathrm{R}^{2}=\mathrm{COOR}, \mathrm{CONMe} \mathrm{e}_{2}, \mathrm{COMe}, \mathrm{C}_{6} \mathrm{H}_{4} \mathrm{~F}$

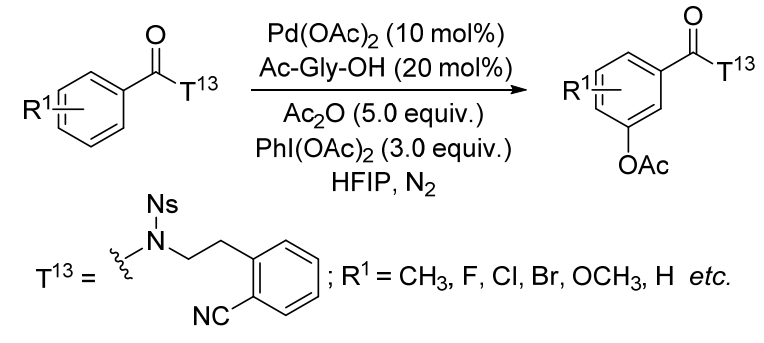

得到间位取代的产物. 苯甲酸的乙酰氧化活性虽然没有 烯烃化高, 但是也以中等到良好产率得到目标产物.

2017 年, Houk 等 ${ }^{[33}$ 通过氭基模板导向实现了苯甲 酸间位烯烃化(Eq. 30)，与苯乙酸、3-苯基丙酸和芐醇等 底物相比, 苯甲酸是具有刚性结构的底物, 模板结构灵 活，通过一系列的模板篮选发现，与底物中模板的构象 相比, 过渡态中模板的变形程度对产物的区域选择性影 响很大，在间位选择性过渡态中模板的变形程度最小.

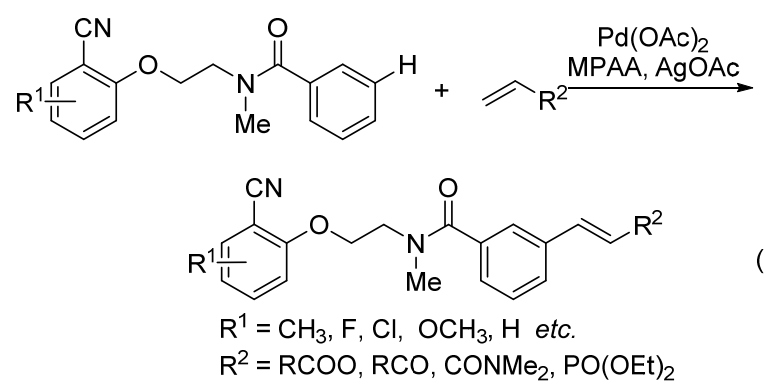

2017 年, $\mathrm{Li}$ 课题组 ${ }^{[34]}$ 以氨基甲酸酯连接氰基模板和 苯胺衍生物, 实现了苯胺衍生物间位烯烃化(Eq. 31). 在 考察范围内邻位和间位取代的苯胺反应活性高，区域选 择性好，对位取代的苯胺以中等到良好产率得到目标产 物，该反应体系同样适用于苯胺间位的乙酰氧化反应， 相比间位烯烃化反应，活性略有降低(Eq. 32).
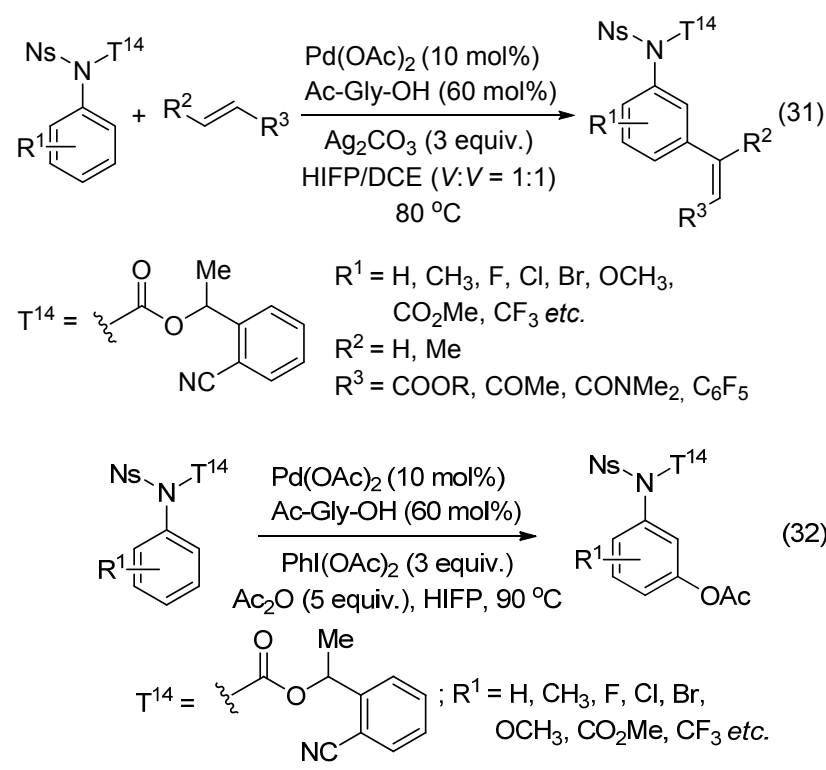
最近, Yu 课题组 ${ }^{[35]}$ 又报道了双官能团氰基模板 $\mathrm{T}^{15}$ 并将其应用于钯催化的苯酚及其衍生物间位烯烃化反 应中(Eq. 33), 吸电子和给电子的取代基都可以高选择 性地得到间位产物. 烯烃化反应后在 $\mathrm{Ni}$ (Xantphos) $\mathrm{Cl}_{2}$ 催 化下与 $\mathrm{ArB}(\mathrm{OH})_{2}$ 反应, 原位芳烃化反应脱除模板, 得 到 1,3-二取代芳香化合物(Eq. 34). 该模板合成方法简 单, 原料廉价易得, 既可辅助间位碳氢活化, 又可作为 官能团发生 $\mathrm{C}-\mathrm{O}$ 断裂, 引入芳基. 该方法可由酚制备 1,3-二取代芳香化合物.

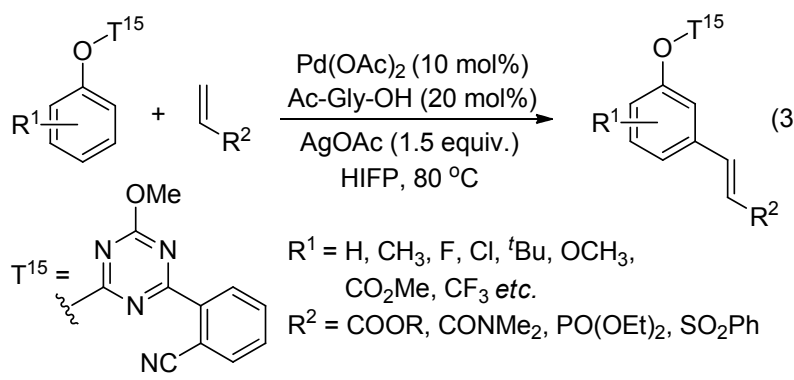

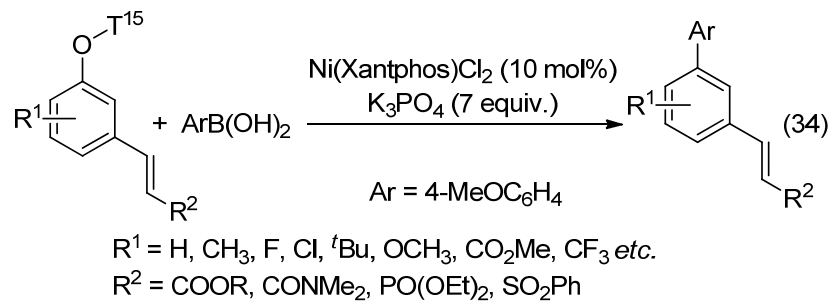

$\mathrm{Xu}$ 课题组 ${ }^{[36]}$ 以 $\mathrm{T}^{16}$ 为模板, 通过芳香季铵盐苯环间 位烯烃化反应实现了芳香叔胺及其衍生物苯环的间位 烯烃化(Eq. 35), 该反应体系以 $\mathrm{Pd}(\mathrm{OAc})_{2}$ 为催化剂, $\mathrm{AgOAc}$ 为氧化剂, 苯环上各种电子效应取代基的邻、 间、对- $N, N$-二甲基苯胺衍生物都高选择性地得到了间位 产物, 烷基、烷氧基、氟和氯取代基都与催化体系有很 好的兼容性, 但是氟和氯取代基导致间位产物产率降 低.

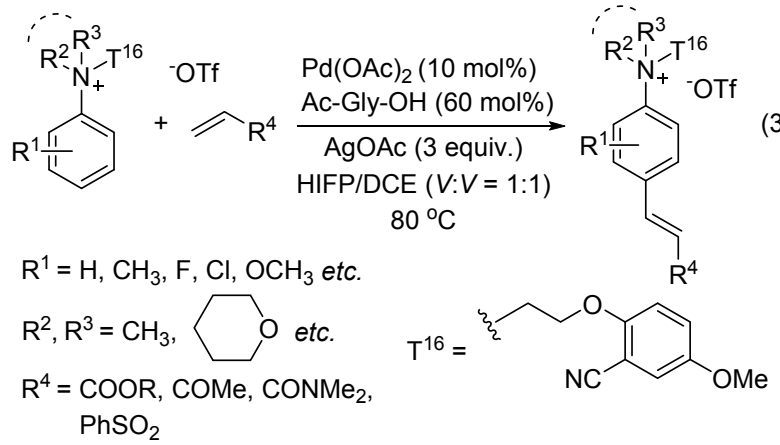

由于氰基模板的配位效应弱, 当有其他配位性强的 试剂或反应物存在时, 氧基不能与催化剂钯有效配位, 因此限制了底物的范围.

\section{2 氮杂环导向的间位官能化}

2015 年, Yu 小组 ${ }^{[37]}$ 报道了基于配位能力强的吡啶 模板导向的芐醇和苯乙醇间位烯烃化(Eq. 36)和碘化反 应(Eq. 37). 通过巧妙设计模板的几何结构成功实现了 间位活化反应，考察范围内对各种取代的茮醇底物都取 得了满意的结果，邻位取代的底物在位阻小的一侧间位 反应生成单取代产物，间位取代底物高产率和选择性地 生成间位一取代产物，对位 $\mathrm{F}$ 和 $\mathrm{COOCH}_{3}$ 取代的茮醇高 选择性地得到间位一取代和二取代的混合产物，二级苄 醇和苯乙醇也能发生间位烯烃化反应。在优化的条件 下，邻、间、对位取代的苄醇以 $64 \% \sim 85 \%$ 的产率高间 位选择性地得到碘代产物。
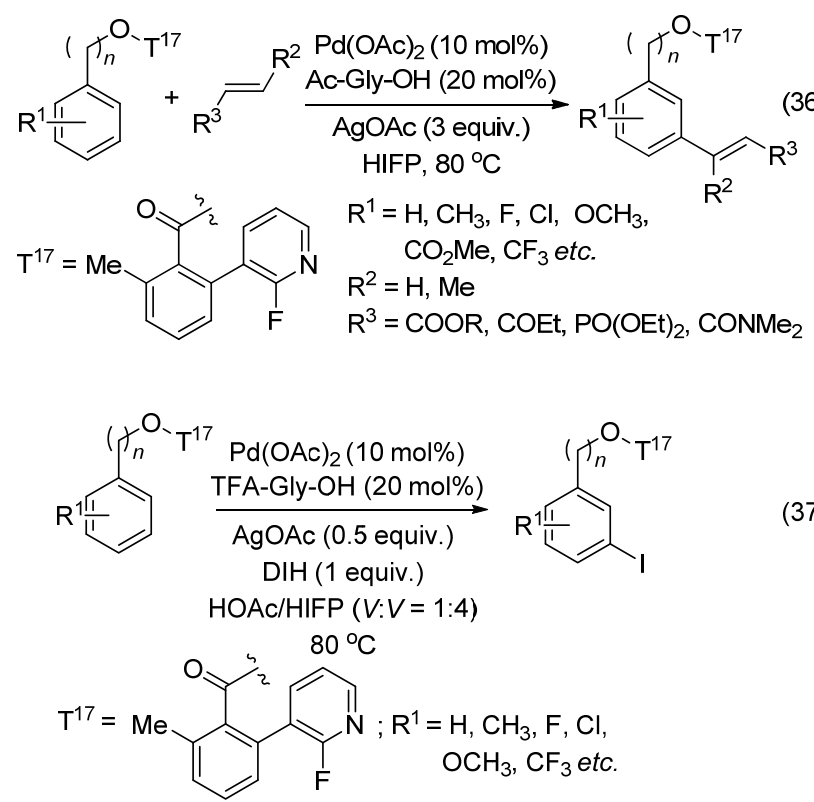

2018 年, $Y u$ 课题组 ${ }^{[38]}$ 合成了 $\mathrm{U}$ 型吡啶模板, 实现了 钯催化苯乙酸间位的烯烃化(Eq. 38), 他们还以 $\mathrm{ArBF}_{3} \mathrm{~K}$ 和 1,3-二碘-5,5-二甲基海因(DIH)作芳基化和碘化试剂, 得到了间位芳基化(Eq. 39)以及碘化产物(Eq. 40). 该反 应体系的底物适用范围广，对各类吸电子和给电子的取 代苯乙酸都有好的兼容性, 䒺乙酸、杂环羧酸和 $\alpha$-取代 苯基乙酸都能发生烯烃化、芳基化和碘化反应，并高选 择性地得到间位取代产物。

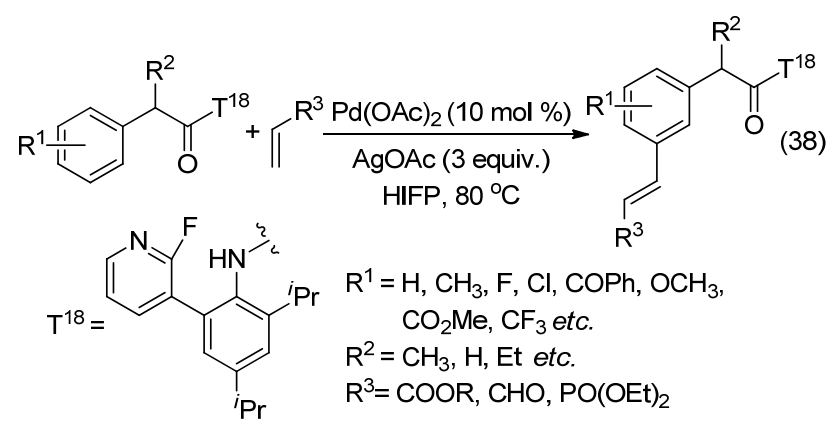


<smiles>[R]C(C(=O)[18OH])c1ccccc1</smiles>

$\mathrm{R}^{1}$<smiles>[R][CH][In]</smiles>
oxidant, additive HIFP, $80^{\circ} \mathrm{C}$

$\mathrm{R}^{1}=\mathrm{H}, \mathrm{CH}_{3}, \mathrm{~F}, \mathrm{Cl}, \mathrm{OCH}_{3}$ etc. $\mathrm{R}^{2}=\mathrm{CH}_{3}, \mathrm{H}, \mathrm{Et}$, OAc etc.

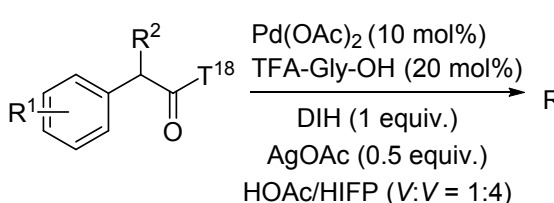
$80^{\circ} \mathrm{C}$

$\mathrm{R}^{1}=\mathrm{H}, \mathrm{CH}_{3}, \mathrm{~F}, \mathrm{Cl}, \mathrm{Br}$, I etc.; $\mathrm{T}^{18}=$<smiles>[R]C(C(=O)[AlH2])c1c[14cH][14cH][14c](I)[14cH]1</smiles>

与乙烯基膦酸酯、丙烯酸酯、烯酮和乙烯基砜等烯 烃化试剂相比，烯丙基醇双键上电子云密度大，在烯烃 的插入过程中，金属中心的电正性越强越有利于烯烃的 插入. 与吡啶相比, 嘧啶中两个氮原子的存在会使电子 云密度减小，与金属配位时，金属中心的电正性增强. 嘧啶的结构与吡啶相似, 作为导向基团替代吡啶保持底 物的 $U$ 型构象. 此外, 嘧啶环可绕碳碳单键旋转, 增加 了氮原子与间位碳氢键接触的机率. 2017 年, Maiti 课题 组 ${ }^{[39]}$ 报道了嘧啶模板导向 $\mathrm{Pd}(\mathrm{OAc})_{2}$ 催化的茮磺酸酯及 其衍生物间位活化反应，该反应分别以烯丙基醇和茮基 烯丙基醚为底物, 在优化的条件下分别得到了 $\beta$-芳基醛 酮和 $\alpha, \beta$-不饱和醛, 他们还将该反应拓展到了 3-苯基丙 酸酯、2-苯基乙基醚和茮基磷酸酯等物质的间位活化反 应中(Scheme 6), 同样得到了满意的结果.

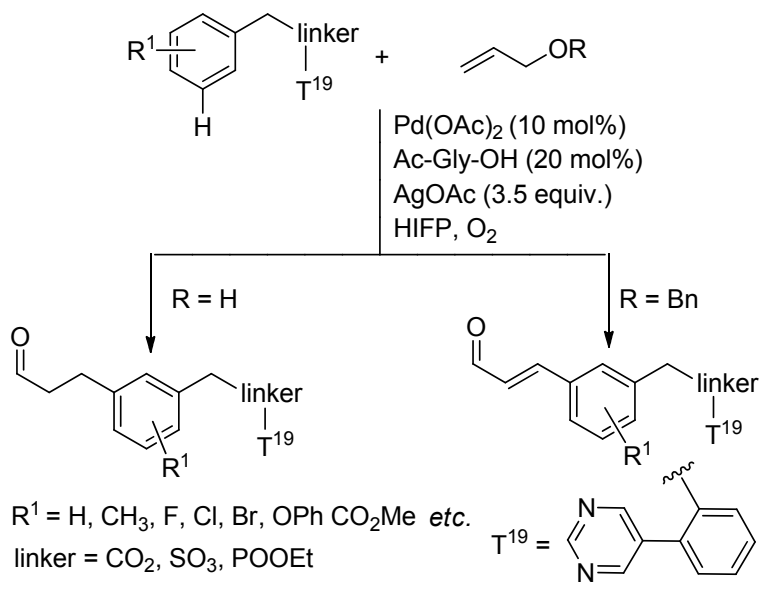

图式 6 嘧啶模板导向间位碳氢键活化反应 Scheme 6 meta-C $-\mathrm{H}$ activation directed by pyrimidine-based template
随后，该课题组 ${ }^{[40]}$ 又将该嘧啶模板用于苠基硅烷 的间位氰化反应中 (Eq. 41), 反应以 $\mathrm{Pd}(\mathrm{OAc})_{2}$ 为催化剂、 $\mathrm{CuCN}$ 作㲵化试剂，茮基硅烷苯环上吸电子取代基和给 电子取代基都具有良好的反应兼容性，对位取代基位阻 大的茮基硅烷也有较高的间位选择性，该反应体系同样 适用于苄磺酸酯、苄基磷酸酯(Eq. 41)、苯乙烷磺酸酯和 苯乙醚(Eq. 42).
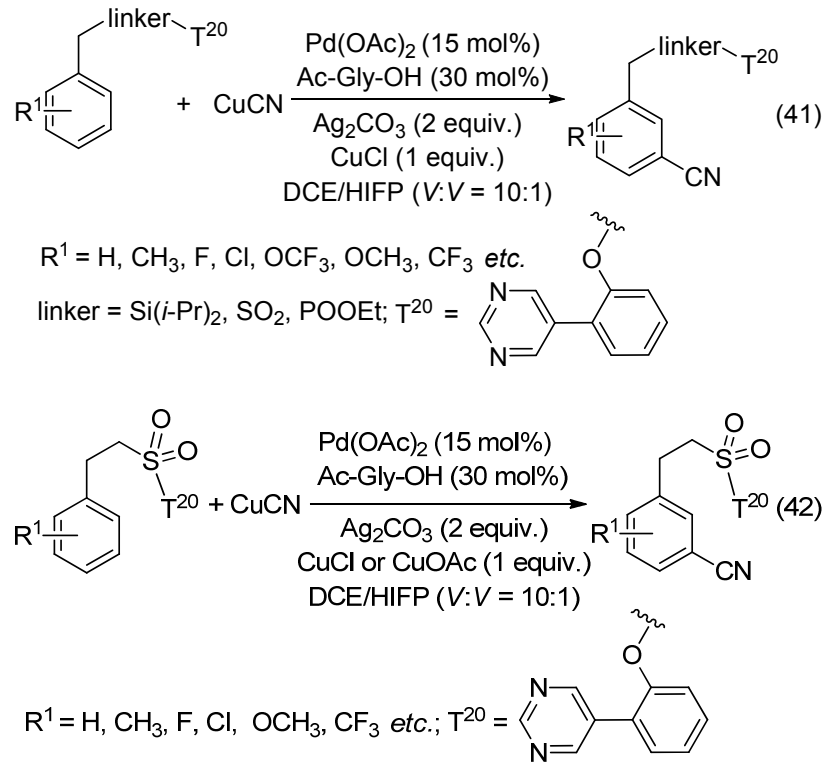

2018 年, Maiti 小组 ${ }^{[41]}$ 又用嘧啶模板导向 3-苯丙醇 以及具有相似结构的长链同系物的苯环间位碳氢键的 活化，碳链的长度使间位碳氢键与导向基参与配位的原 子间间隔 20 个原子以上，反应以 $\mathrm{Pd}(\mathrm{OAc})_{2}$ 为催化剂， 在不同的反应条件下可高选择性地得到间位烷基化(Eq. 43)、烯烃化(Eq. 44)、乙酰氧化(Eq. 45)和氰化的产物(Eq. 46), 成功实现了 $\mathrm{C}-\mathrm{C}$ 及 $\mathrm{C}-\mathrm{O}$ 的构建. 通过对 $n$ 为 3,5 和 10 的底物的烯烃化反应速率的研究, 他们认为随着 $n$ 值的增加, 反应速率减小.

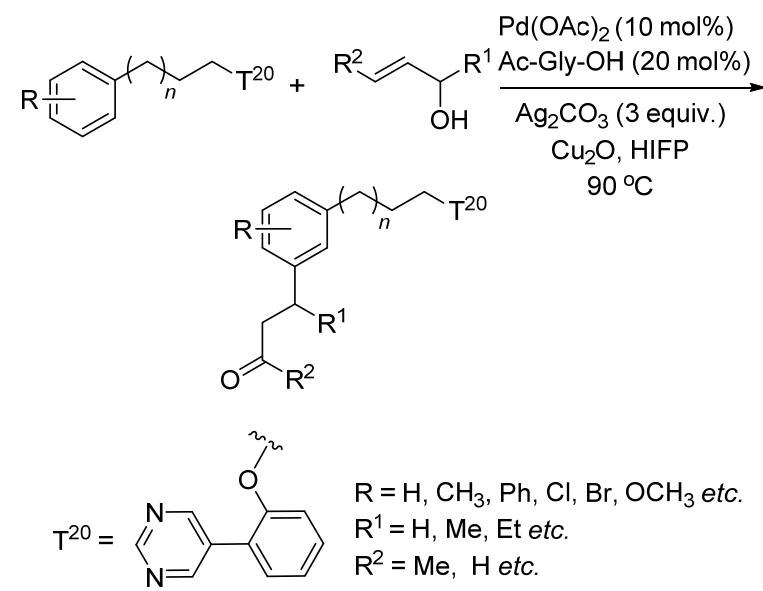




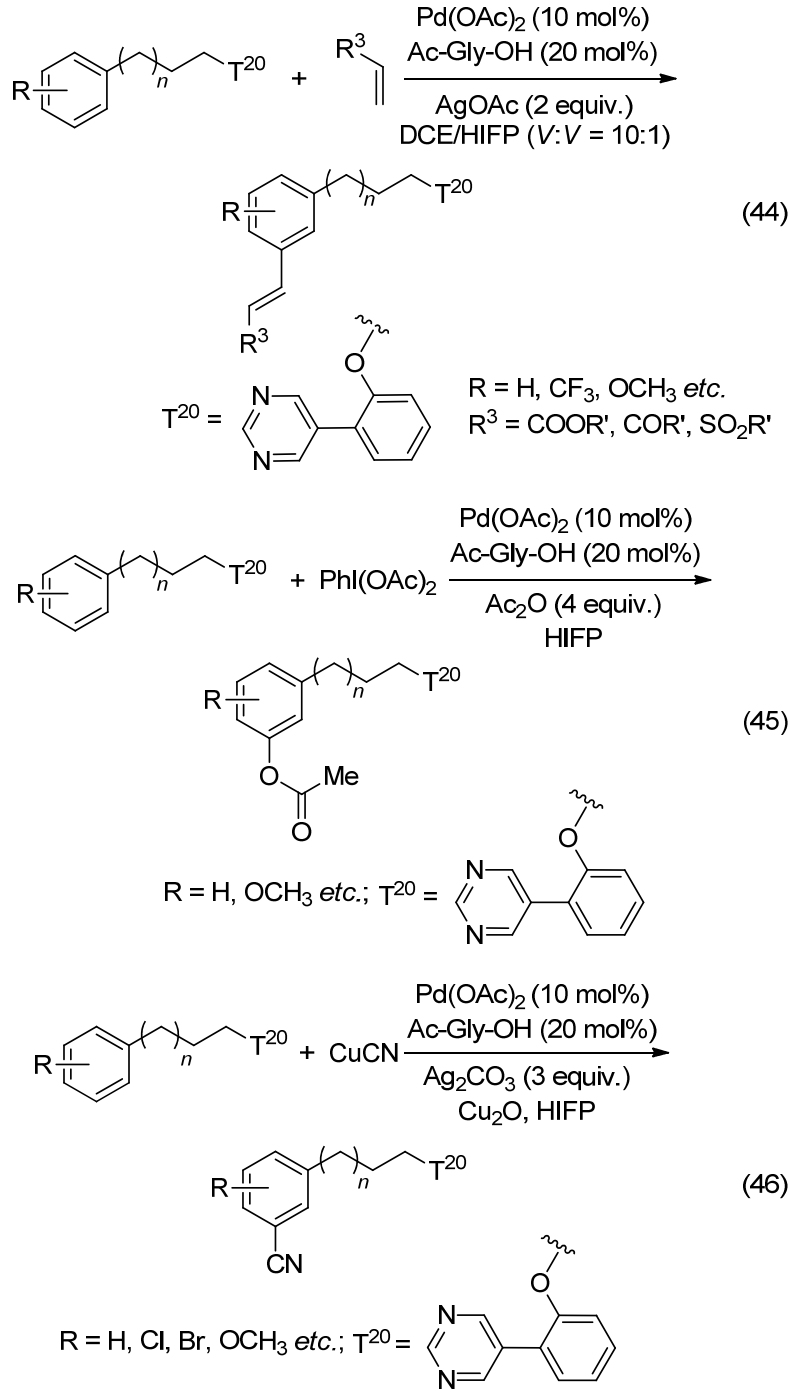

最近, Wang 课题组 ${ }^{[22]}$ 以嘧啶模板 $\mathrm{T}_{19}$ 为导向基实现 了 3-苯基-1,2-丙二醇及其衍生物苯环间位烯烃化反应 (Eq. 47), 反应体系以 $\mathrm{Pd}(\mathrm{OAc})_{2}$ 为催化剂, $\mathrm{AgF}$ 为氧化剂, $\mathrm{Na}_{2} \mathrm{CO}_{3}$ 为添加物, 催化体系适用范围广, 苯环上各种电 子效应的邻、间、对位取代二醇都选择性得到间位取代 产物, 丙烯酸酯、 $N, N$-二甲基丙烯酰胺、乙烯基膦酸二 乙酯、乙烯基砜和五氟代苯乙烯都可作为烯烃化试剂.

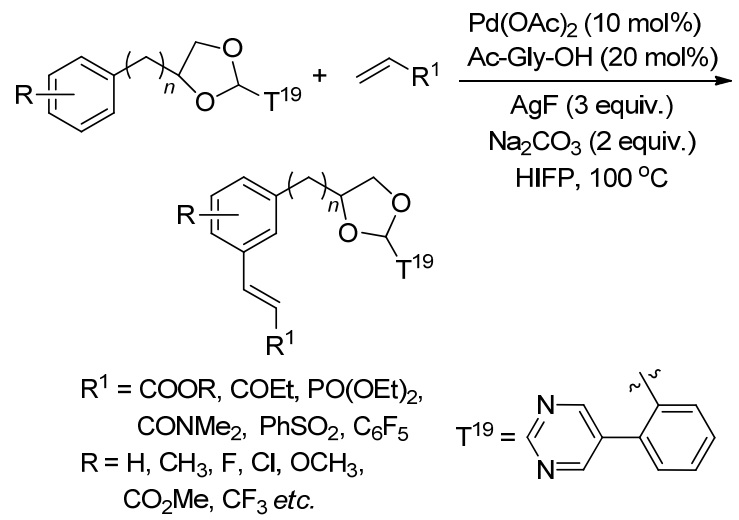

2017 年, Maiti 课题组 ${ }^{[43]}$ 以硫酰基连接 8-硝基喹啉 模板, 实现了苄磺酸酯间位烯烃化(Eq. 48)和乙酰氧化 (Eq. 49)反应，反应体系适用范围广， $\alpha, \beta$-不饱和酮、丙烯 酸酯、 $N, N$-二甲基丙烯酰胺、乙烯基膦酸二乙酯、乙烯 基砜和丁烯二酸二甲酯等一系列烯烃和芐磺酸酯都得 到了较高的产率和选择性，含有不同化学性质取代基的 芐磺酸酯衍生物与烯烃反应也高产率地得到间位烯烃 化产物. 间位单取代产物可以继续与烯烃发生反应，得 到间位带相同或不同取代基的二烃基取代的茮磺酸酯. 反应之所以有高的反应活性和选择性原因如下: (1)硫酰 基氧原子间的电子效应和空间效应以及硫原子 $\mathrm{sp}^{3}$ 杂化 方式增强了导向基间位导向能力; (2)硝基与金属钯之间 的作用力以及硝基氧原子与底物中芳基碳氢键之间的 次级效应有利于间位产物的生成.

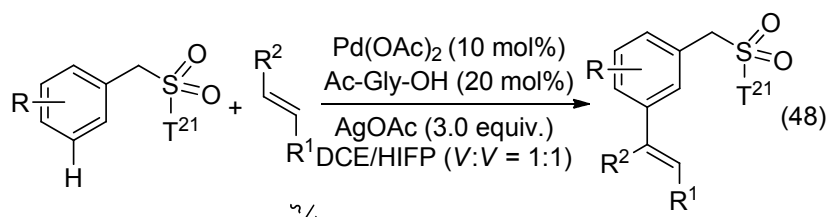

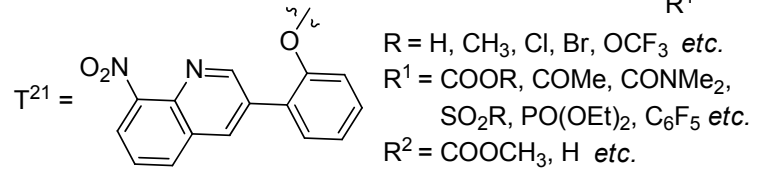

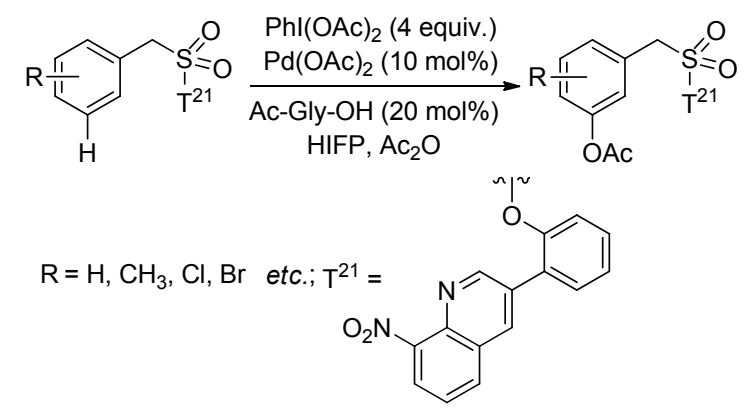

虽然 U-型模板在间位选择性活化中表现出优越的 性能，但此策略需要设计特定模板，模板以共价键与底 物结合, 反应后需借助化学方法脱除模板, 限制了该方 法的应用。

\section{2 降冰片烯介导间位官能化反应}

$\mathrm{Yu}$ 课题组采用降冰片烯作为瞬态介质, 使用简单 的邻位导向取代基来实现苯环间位选择性碳氢键活化. 2015 年, $\mathrm{Yu}$ 等 ${ }^{[44]}$ 报道了 $\mathrm{Pd}(\mathrm{OAc})_{2}$ 催化、降冰片烯(NBE) 瞬态介导、具有给电子效应取代基的吡啶类配体作用下 下苯乙酰胺苯环间位的烷基化以及芳基化反应(Scheme 7), 在优化的条件下该反应对各种酰胺的衍生物都得到 了较好的结果，但是该反应体系适用范围有限，对于酰 
胺的乙基化反应只得到了 $21 \%$ 的产物，对于芳基化反 应，当芳基化试剂邻位无配位基团时也不能发生反应. 他们推测反应机理为: 酰胺基团诱导金属钯活化苯环邻 位碳氢键, 之后降冰片烯双键与钯进行配位, 随后发生 Catellani 反应使钯对苯环间位进行活化, 随后降冰片烯 离去，钯插入碳卤键中发生异构化反应，还原消除得到 间位活化产物. 反应过程中副产物 I 和 II 的生成会导致 无法得到间位活化产物, 配体和降冰片烯的加入能够抑 制副产物 I 的生成, 对反应非常重要. 随后他们 ${ }^{[45]}$ 通过
优化降冰片烯结构和配体，使用 $\mathrm{NBE}-\mathrm{CO}_{2} \mathrm{Me}$ 作瞬态介 质，成功克服了上述缺点，拓展了底物适用范围，苯乙 酰胺衍生物可以与各种长链的烷基碘和芳基碘发生反 应(Eq. 50). Shi 课题组 ${ }^{[46]}$ 通过在苯乙胺底物中引入含有 $\mathrm{N}, \mathrm{O}$ 二齿配位的乙二酰基导向基，也成功克服了上述缺 点，实现了苯乙胺衍生物间位芳烃化反应，该反应体系 以降冰片烯作为瞬态介质，对各种性质取代基的碘苯以 及苯乙胺衍生物都有很好的间位选择性(Eq. 51).

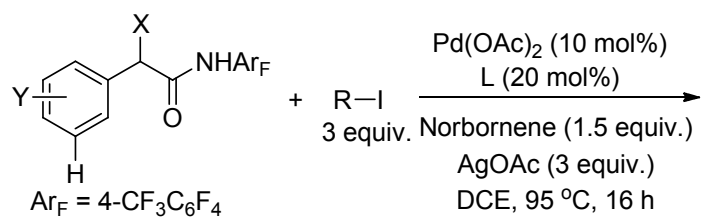

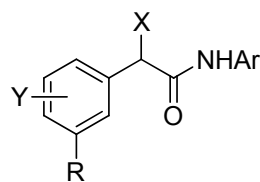<smiles>COc1c2c(nc3c1CCCO3)CCC2</smiles>
$\mathrm{R}=\mathrm{Me}, \mathrm{CH}_{2} \mathrm{CO}_{2} \mathrm{Et}, \mathrm{CH}_{2} \mathrm{Ar}$,<smiles>CC(=O)c1ccc[R1]c1C</smiles>

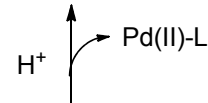
$\mathrm{R}^{1}=\mathrm{H}, \mathrm{CH}_{3}, \mathrm{Cl}, \mathrm{Br}$, F etc.

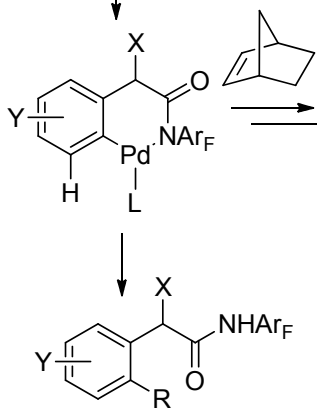

$\mathrm{Y}=\mathrm{H}, \mathrm{CH}_{3}, \mathrm{Cl}, \mathrm{Br}, \mathrm{OCH}_{3}, \mathrm{CF}_{3}$ etc. $\mathrm{X}=\mathrm{H}, \mathrm{CH}_{3}, \mathrm{OAc}, \mathrm{OBn}$ etc.

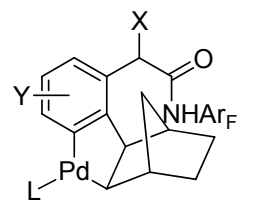

Scheme 7 meta-C $-\mathrm{H}$ activation directed by transient mediator

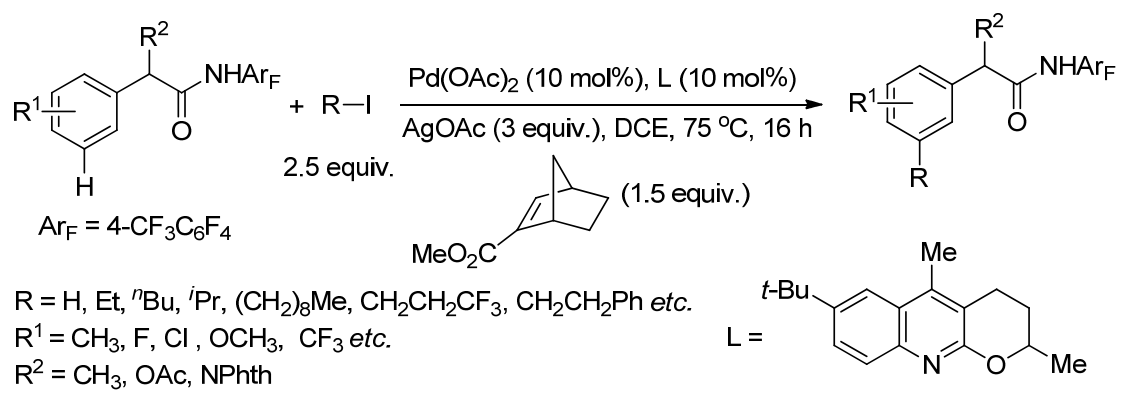

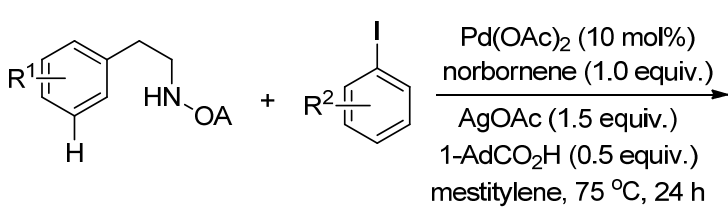

$\mathrm{R}^{1}=\mathrm{H}, \mathrm{CH}_{3}, \mathrm{~F}, \mathrm{Cl}, \mathrm{OCH}_{3}, \mathrm{CF}_{3}$ etc.

mestitylene, $75^{\circ} \mathrm{C}, 24 \mathrm{~h}$

$\mathrm{R}^{2}=\mathrm{CH}_{3}, \mathrm{~F}, \mathrm{Cl}, \mathrm{Br}, \mathrm{I}, \mathrm{OCH}_{3}, \mathrm{CO}_{2} \mathrm{Me}, \mathrm{CF}_{3}, \mathrm{NO}_{2}$ etc. 1-AdCO ${ }_{2} \mathrm{H}=1$-adamantanecarboxylic acid<smiles>N#[P+]NC(=O)C(=O)CC=O</smiles> 
Dong 课题组 ${ }^{[47]}$ 以 $\mathrm{Pd} / \mathrm{NBE} / \mathrm{AsPh}_{3}$ 催化体系实现了苯 乙胺及其衍生物间位的芳基化反应, 产率最高可达 $80 \%$, 底物中胺基作为导向基活化邻位, NBE 发挥导向 基团作用, $\mathrm{AsPh}_{3}$ 可能作为配体来稳定过渡态(Eq. 52).

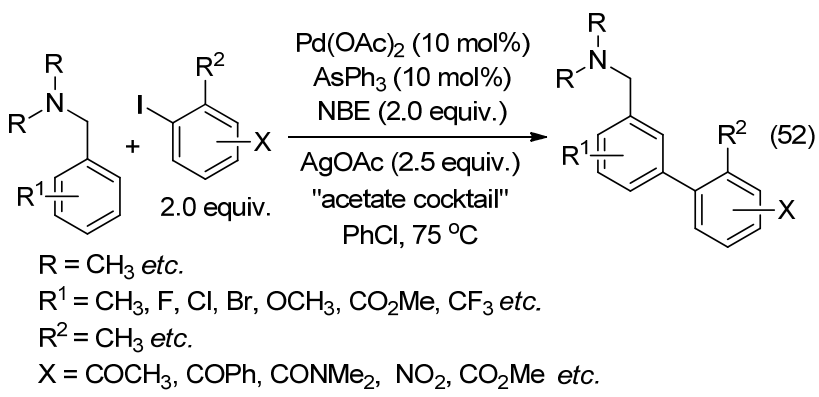

$\mathrm{Yu}$ 课题组 ${ }^{[48]}$ 首次报道了 $\mathrm{Pd}(\mathrm{OAc})_{2}$ 催化、 NBE$\mathrm{CO}_{2} \mathrm{Me}$ 瞬态介导苯胺衍生物(Eq. 53)和酚衍生物(Eq. 54) 间位胺基化和炔基化反应(Eq. 55), 配体和 $\mathrm{NBE}-\mathrm{CO}_{2} \mathrm{Me}$ 对反应起到了重要作用, 吲哚、二氢吲哚、吲唑及其衍 生物都以良好到优秀产率得到间位氨基化和炔基化产 物.

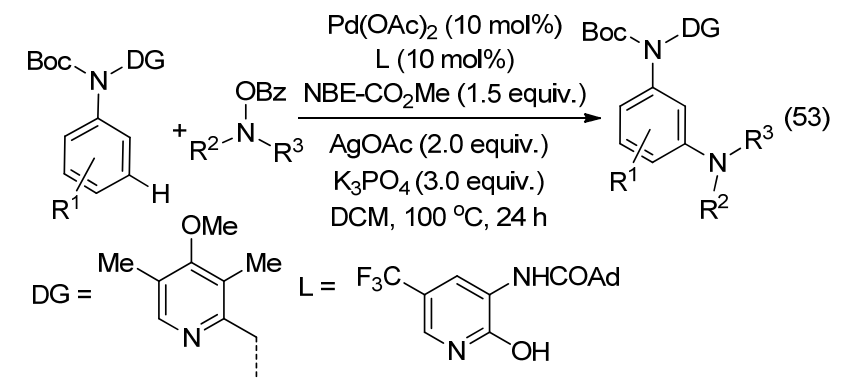

$\mathrm{R}^{1}=\mathrm{H}, \mathrm{CH}_{3}, \mathrm{SMe}, \mathrm{Et}, \mathrm{Bn}, \mathrm{OCH}_{3}, \mathrm{Ph}, \mathrm{F}, \mathrm{Cl}, \mathrm{Br}, \mathrm{CO}_{2} \mathrm{Me}$, COPh etc. $\mathrm{R}^{2}, \mathrm{R}^{3}=\square, \square$ OAc, $\square$-OTBS, etc.

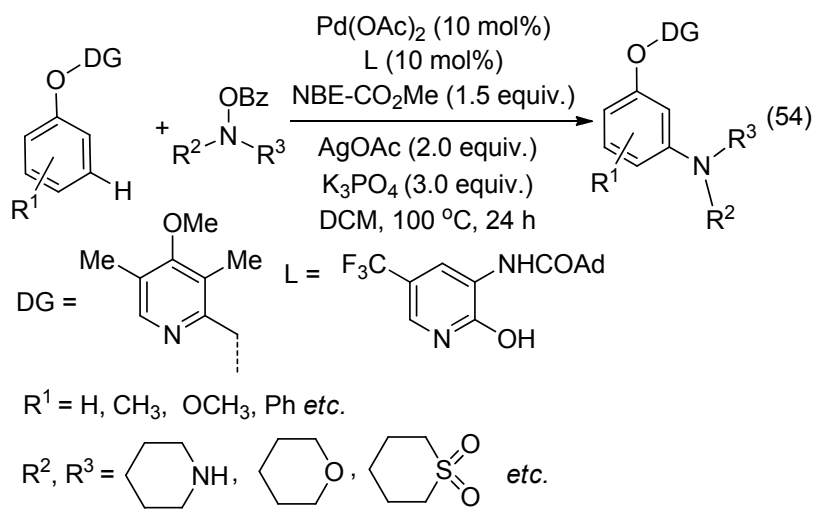

$\mathrm{Yu}$ 课题组 ${ }^{[49]}$ 首次以吡啶、呋喃、噻吩、喹啉、苯 并吡唑等杂环碘代物作为芳基化试剂, 实现了苯胺、苯 酚、杂环芳胺(Scheme 8)、2-芐基杂环芳胺及其衍生物 (Eq. 56)间位芳基化反应. 催化体系以降冰片烯作瞬态

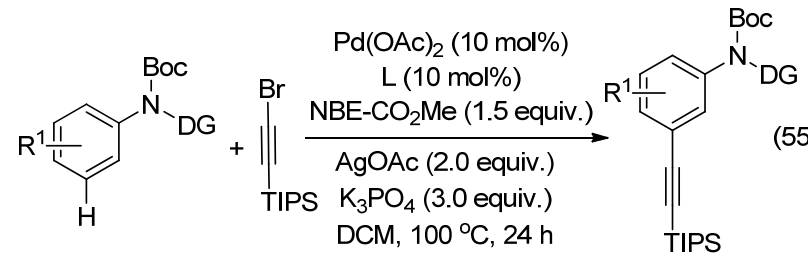

$\mathrm{R}^{1}=\mathrm{H}, \mathrm{CH}_{3}, \mathrm{OCH}_{3}, \mathrm{Ph}, \mathrm{Bn}, \mathrm{F}, \mathrm{Cl}, \mathrm{Br}$ etc.<smiles>CCc1ncc(C)c(OC)c1C</smiles>

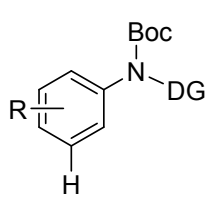

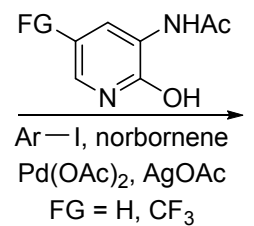

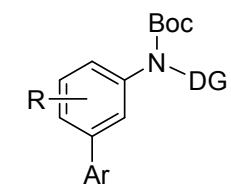

$\mathrm{R}=\mathrm{H}, \mathrm{CH}_{3}$, Et, Bn, Ph, $\mathrm{OCH}_{3}$, $\mathrm{F}, \mathrm{Cl}, \mathrm{CF}_{3}$, SMe etc.<smiles>COc1c(C)cnc(I)c1C</smiles>

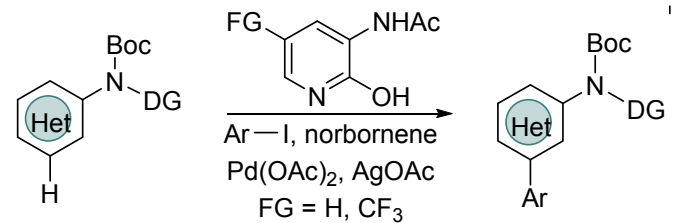

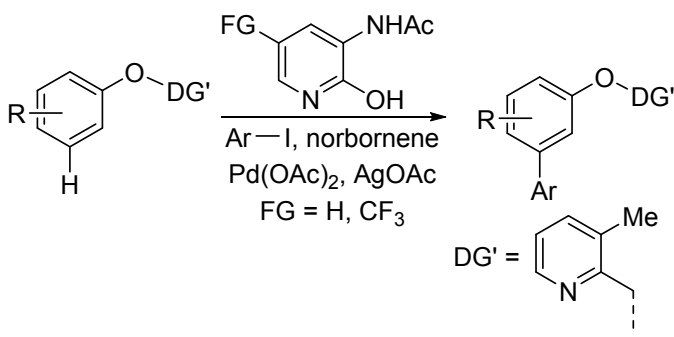

图式 8 苯胺、苯酚和杂环芳胺间位芳基化反应

Scheme 8 meta-C $-\mathrm{H}$ arylation of phenylamine, phenol and heterocycle phenylamine

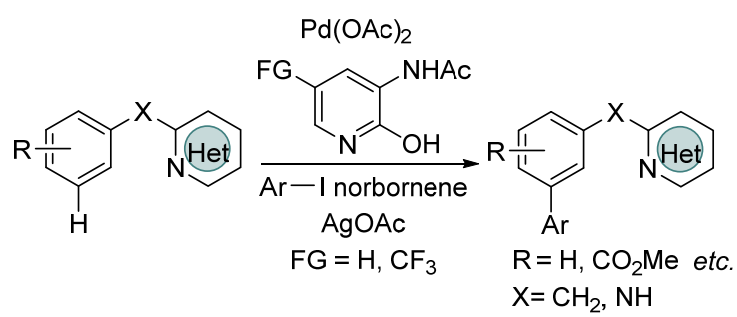

介质，以 3-乙酰氨基-2-差基吡啶作配体，在底物和芳基 化试剂考察范围内, 得到了较好的结果.

2017 年, $\mathrm{Yu}$ 课题组 ${ }^{[50]}$ 以 $\mathrm{Pd}(\mathrm{OAc})_{2}$ 催化、NBE$\mathrm{CO}_{2} \mathrm{Me}$ 瞬态介导实现了苯乙酸及其衍生物间位芳基化 反应(Eq. 57), 反应以乙酸底物中羧基作导向基团，吡啶 类化合物作配体，对各种电子性质的芳基碘都有很好的 反应活性，但是杂环芳基碘不能作为芳基化试剂。 

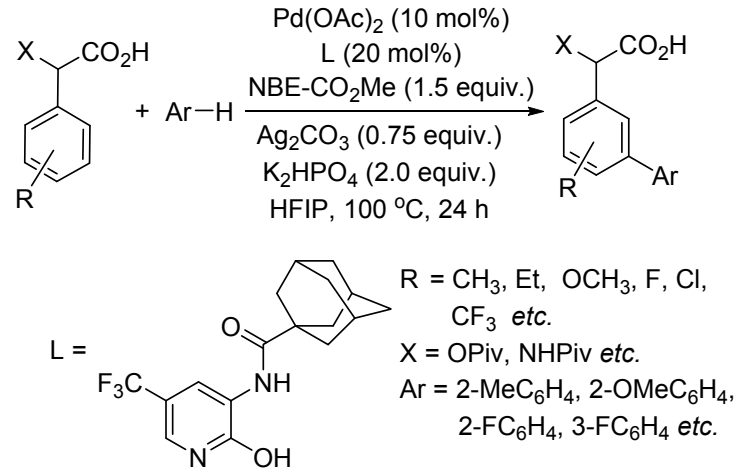

$\mathrm{Yu}$ 课题组 ${ }^{[51]}$ 将瞬态介导催化体系应用到对硝基苯 磺酰基保护的苯胺、苄胺以及 2-芳基苯胺(Eq. 58)的间 位芳基化反应中，首次以催化剂量(20 mol\%)的降冰片 烯作瞬态介质, 以 4-乙酰基吡啶作配体, 考察范围内的 各种苯胺和 2-芳基苯胺均有好的反应活性, 各种性质取 代基取代的芳基碘、邻位含有配位基团的芳基溴都可作 为芳基化试剂，这是芳基溴作芳基化试剂的首例报道， 但是对于苄胺只有苯基甘氨酸能与邻位含有配位基团 的芳基碘发生反应. 随后他们 ${ }^{[52]}$ 改变反应的配体和瞬 态介质, 以 $\mathrm{NBE}-\mathrm{CO}_{2} \mathrm{Me}$ 为瞬态介质, 吡啶酮为配体, 该催化体系对各种茮胺衍生物芳基化都有好的催化效 果，该反应体系对茮胺衍生物的胺基化、氯化同样有好 的催化效果, 而且杂环芳基碘也可作为芳基化试剂(Eq. 59). 2018 年, Ding 课题组 ${ }^{[53]}$ 报道了对硝基磺酰基保护苄 胺的烷基化反应, 反应以 NBE5 为瞬态介质, 吡啶为配 体, 当 $\mathrm{CH}_{3} \mathrm{I}$ 和 $\mathrm{ICH}_{2} \mathrm{COOEt}$ 作烷基化试剂时, 以中等到 优秀产率得到间位烷基化产物，而 $\mathrm{CH}_{3} \mathrm{CH}_{2} \mathrm{I}$ 作烷基化试 剂, 当 $\mathrm{R}^{1}$ 是 $\mathrm{Me}$ 和 $\mathrm{F}$ 时分别得到了 $24 \%$ 和 $27 \%$ 的间位烷 基化产物(Eq. 60).

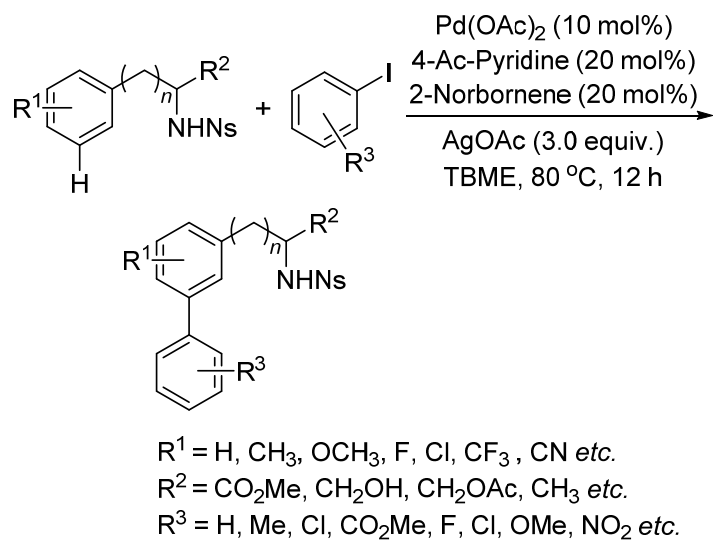

2017 年, $\mathrm{Yu}$ 课题组 ${ }^{[54]}$ 报道了苄磺酰胺及其衍生物 间位烷基化以及芳基化反应 (Eq. 61). 该体系以 $\mathrm{Pd}(\mathrm{OAc})_{2}$ 为催化剂 $\mathrm{NBE}-\mathrm{CO}_{2} \mathrm{Me}$ 为瞬态介质, 异喹啉为 配体，该催化体系适用范围广，对各种性质取代基取代
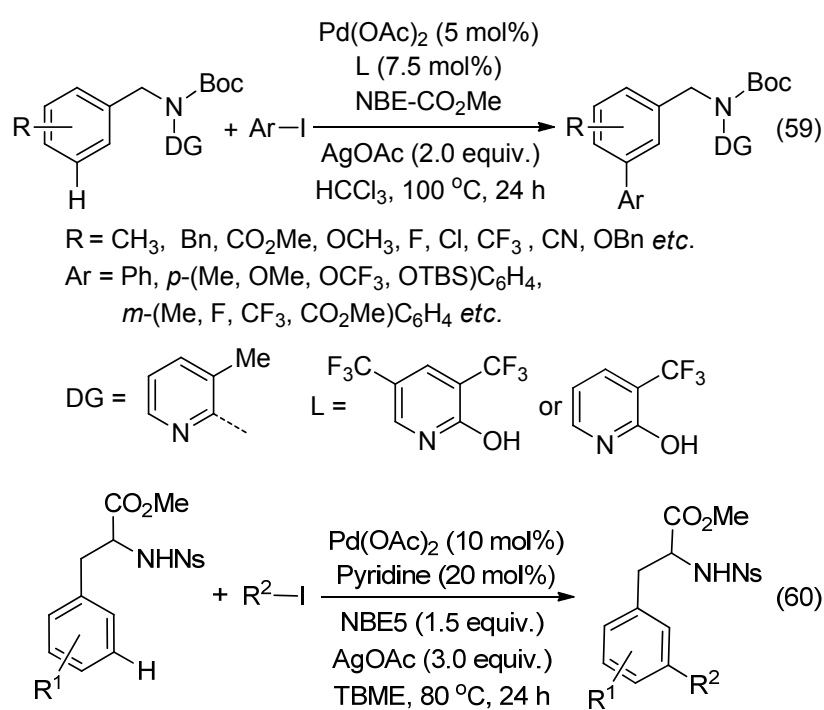

$\mathrm{R}^{1}=\mathrm{H}, \mathrm{CH}_{3}, \mathrm{OCH}_{3}, \mathrm{~F}, \mathrm{Cl}, \mathrm{CF}_{3}, \mathrm{Br}$ etc. $\mathrm{R}^{2}=\mathrm{CH}_{3}$, Et, $\mathrm{CH}_{2} \mathrm{COOEt}$ etc.

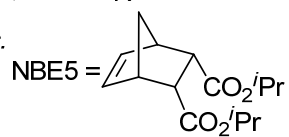

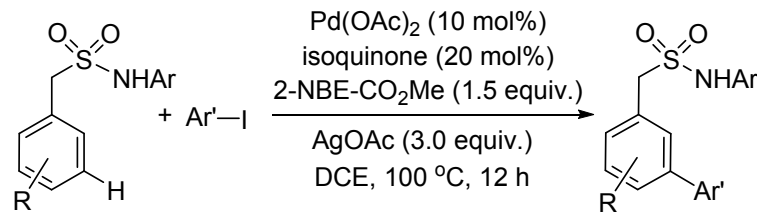

$\mathrm{R}=\mathrm{H}, \mathrm{CH}_{3}, \mathrm{OCH}_{3}, \mathrm{~F}, \mathrm{Cl}, \mathrm{CF}_{3}$ etc $\mathrm{Ar}^{\prime}=p-\left(\mathrm{Me}, \mathrm{C}_{6} \mathrm{H}_{5}, \mathrm{OMe}, \mathrm{F}, \mathrm{Cl}\right) \mathrm{C}_{6} \mathrm{H}_{4}$, $m-\left(\mathrm{Me}, \mathrm{NO}_{2}\right) \mathrm{C}_{6} \mathrm{H}_{4}$, F-pyridyl etc.<smiles>N#Cc1cc(C(F)(F)F)cc(C(F)(F)F)c1</smiles>

的苄磺酰胺都有高的催化活性，芳基化试剂可以是各种 取代的芳基碘和杂环芳基碘.

Ferreira 课题组 ${ }^{[55]}$ 首次以瞬态介导催化体系实现了 苄醇及其衍生物间位芳基化(Scheme 9)，该体系以 Pd-

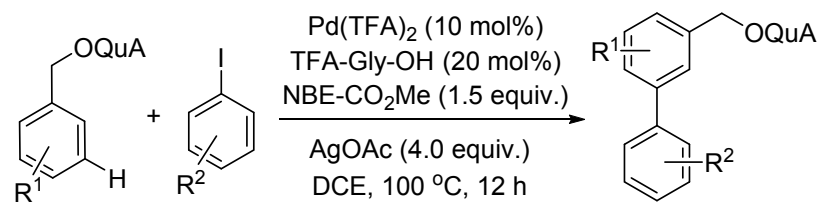

$\mathrm{R}^{1}=\mathrm{H}, \mathrm{CH}_{3}, \mathrm{OBn}, \mathrm{Ph}, \mathrm{OCH}_{3}, \mathrm{~F}, \mathrm{Cl}, \mathrm{CF}_{3}$ etc.

$\mathrm{R}^{2}=\mathrm{CH}_{3}, \mathrm{CO}_{2} \mathrm{Me}, \mathrm{COMe}, \mathrm{NO}_{2}, \mathrm{OCH}_{3}, \mathrm{~F}, \mathrm{Cl}, \mathrm{CF}_{3}$ etc.
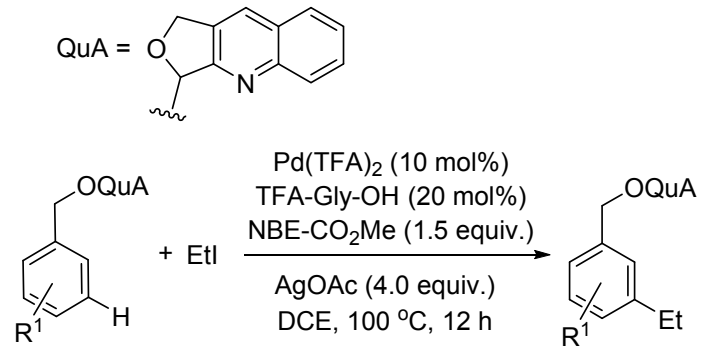

图式 9 苄醇及其衍生物间位芳基化和乙基化

Scheme 9 meta-C- $\mathrm{H}$ arylation and ethylation of benzyl alcohol derivatives 
$(\mathrm{TFA})_{2}$ 为催化剂, $\mathrm{NBE}-\mathrm{CO}_{2} \mathrm{Me}$ 为瞬态介质, TFA-Gly$\mathrm{OH}$ 为配体, 考察范围内各种取代苄醇和取代芳基碘都 有较高的反应活性和选择性.

$\mathrm{Yu}$ 课题组 ${ }^{[56]}$ 以 $\mathrm{Pd}(\mathrm{OAc})_{2}$ 为催化剂, $\mathrm{NBE}-\mathrm{CO}_{2} \mathrm{Me}$ 为 瞬态介质，喹啉酮为配体，实现了苯甲酫及其衍生物间 位芳基化, 苯甲醛首先与烷基锂试剂试剂反应, 同时以 叔丁基二甲基氯硅烷( $\mathrm{TBSCl}$ )捕获羟基, 在醛分子中引 入导向基, 然后再与芳基碘反应(Eq. 62).

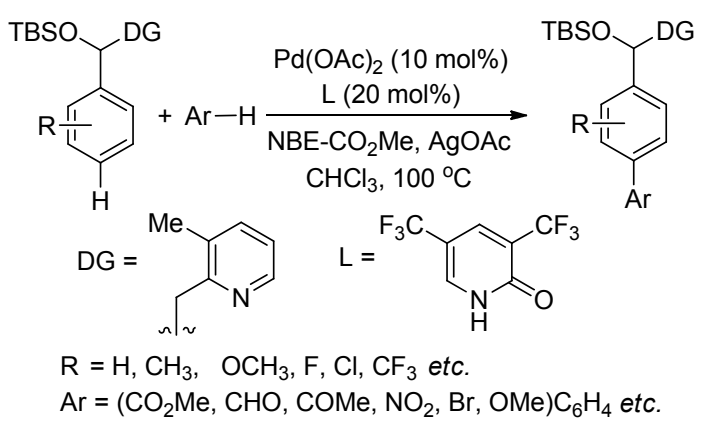

瞬态介导间位活化反应主要是围绕配体和瞬态介 质的优化展开的, 以实现不同底物的间位碳氢键活化.

\section{3 配体次级效应促进间位官能化反应}

Kanai 小组 ${ }^{[57]}$ 报道了另一策略来实现苯环间位碳氢 活化, 利用具有次级作用的双官能配体, 将具有较强成 氢键能力的腿结构与联吡啶配体巧妙结合在一起, 在温 和的条件下, 腿结构较易与底物中的氧原子形成氢键, 配体联吡啶与催化剂 Ir 配位, 通过调整连接联吡啶与嫝 结构的桥使金属中心靠近间位(Scheme 10), 成功实现 了具有多种酰氧官能团取代的芳香族化合物的间位硼 化反应. 该小组发现通过调整配体中的取代基、嫝中的 取代基可加速硼化反应的进行, 当 $\mathrm{R}^{1}$ 是给电子的取代 基 $t$ - $\mathrm{Bu}$ 时, 金属 $\mathrm{Ir}$ 中心的电子云密度增加; 由于反应是 通过扭曲结构进行的, 因此, $\mathrm{R}^{2}=\mathrm{CH}_{3}$ 时联吡啶和苯环 之间会保持一定角度, 有利于反应进行; 而 $\mathrm{R}^{3}$ 会导致嫝

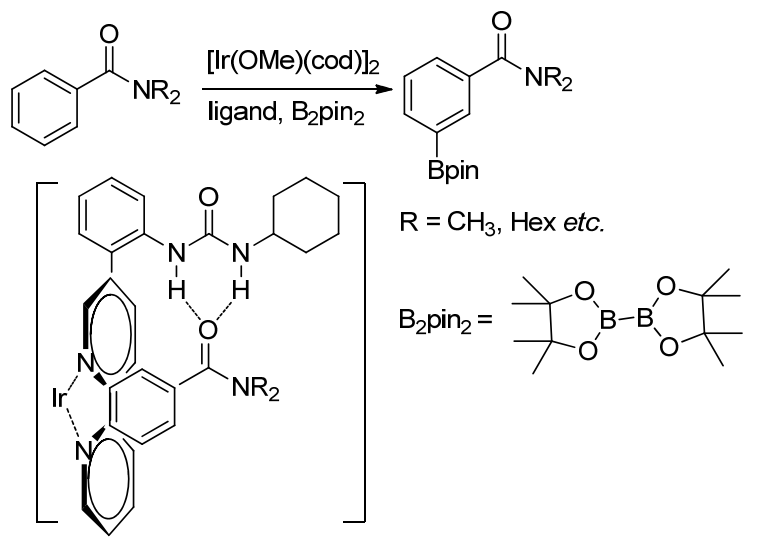

图式 10 氢键促进间位活化

Scheme 10 Hydrogen bond accelerated meta-C $-\mathrm{H}$ activation
结构域底物形成氢键能力的改变. 底物氮原子上的取代 基的位阻效应以及与腿结构发生配位的原子发生变化 会导致产物发生变化(图 5) ${ }^{[58]}$. Sunoj 等 ${ }^{[59]}$ 对该反应体系 的机理进行了研究, 他们认为除了配体中嫝结构与底物 中原子间的氢键作用力, 底物中 $\mathrm{C}-\mathrm{H}$ 与吡啶氮原子、 吡啶配体 $\pi 、 \mathrm{~B}_{2} \mathrm{pin}_{2}$ 中氧原子间的非共价键作用对产物 的区域选择性也起到了重要作用.

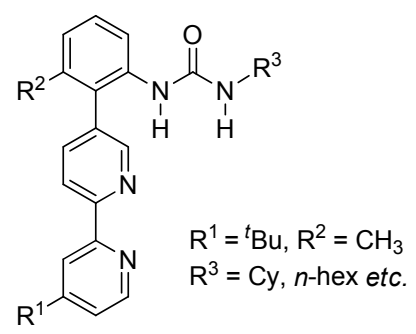

图 5 具有氢键作用力的不同取代基的配体

Figure 5 Design of ligand to accelerate the reaction

Nakao 等 ${ }^{[60]}$ 通过路易斯酸碱的相互作用力, 实现了 苯甲酰胺以及吡啶环间位嗍化反应, 通过路易斯酸 $\mathrm{Al}$ 识别底物酰胺或吡啶环中的碱氮原子, 联吡啶与催化剂 Ir 配位，使 Ir 活化苯甲酰胺和吡啶环的间位(Scheme 11).

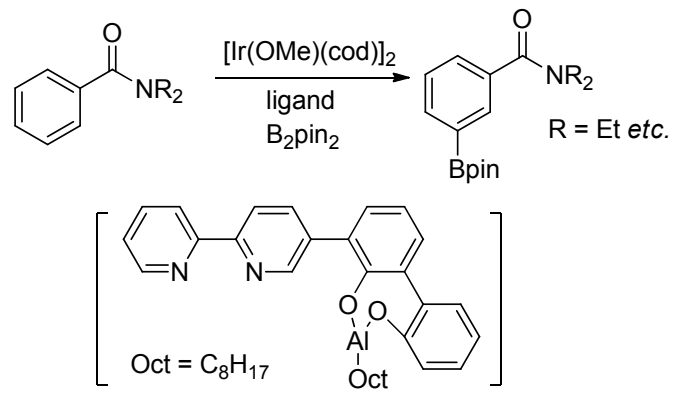

图式 11 路易斯酸碱作用力促进间位活化

Scheme 11 Interaction between Lewis acid and base accelerated meta-C-H activation

Chattopadhyay 等 ${ }^{[61]}$ 利用配合物与底物的静电作用 力以及配合物中嗍原子与底物氮原子的次级作用力实 现了苯甲醛间位硼化反应. 首先反应中苯甲醛与胺生成 亚胺, 借助静电作用和次级效应使催化剂活化亚胺的间 位发生嗍化反应(Scheme 12).

Phipps 课题组 ${ }^{[62]}$ 借助离子对相互作用实现了芳香 季铵盐苯环间位硼化反应, 该反应中底物是含有正电荷 的季铵盐, 配体则含有磺酸根负离子, 磺酸根与季铵盐 相互作用, 使催化剂 Ir 接近苯环间位碳氢, 从而得到间 位嗍化产物(Scheme 13). 他们 ${ }^{[63]}$ 还将该配体应用到三 氟乙酰茮胺、三氟乙酰苯乙胺和三氟乙酰苯丙胺衍生物 间位嗍化反应中，通过研究发现，该反应的区域选择性 与磺酸根与酰胺氮原子上氢原子之间的氢键作用力有 关(Scheme 14). 

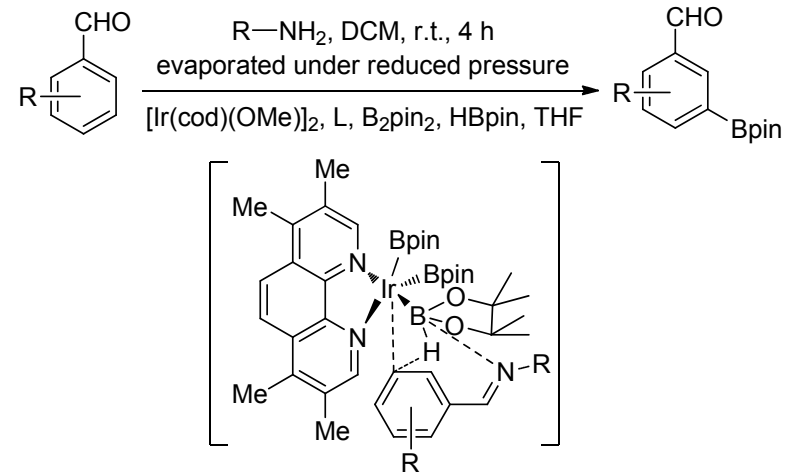

$\mathrm{R}=\mathrm{H}, \mathrm{CH}_{3}, \mathrm{Et}, \mathrm{CO}_{2} \mathrm{Me}, \mathrm{Ph}, \mathrm{OCH}_{3}, \mathrm{~F}, \mathrm{Cl}, \mathrm{CF}_{3}, \mathrm{CN}$ etc.<smiles>Cc1cnc2c(ccc3c(C)c(C)cnc32)c1C</smiles>

图式 12 静电作用力促进间位活化

Scheme 12 Electrostatic interaction accelerated meta-C $-\mathrm{H}$ activation

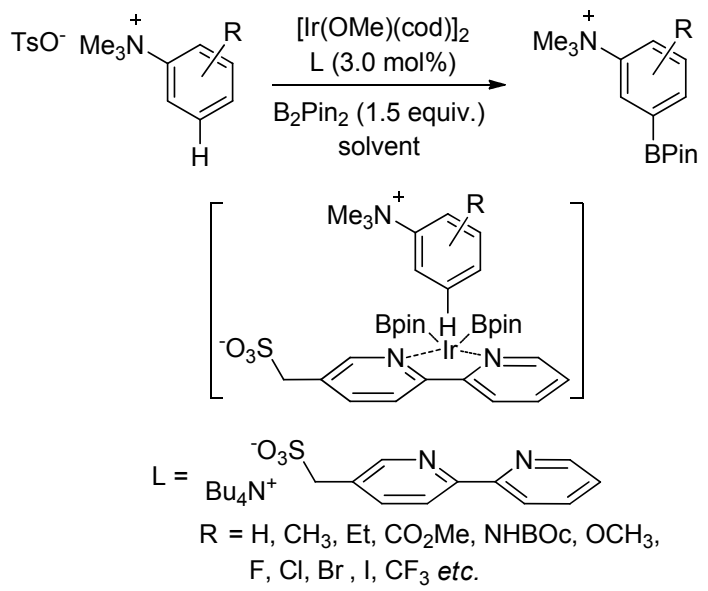

图式 13 离子对作用力促进间位活化

Scheme 13 Ion pair accelerated meta-C- $-\mathrm{H}$ activation

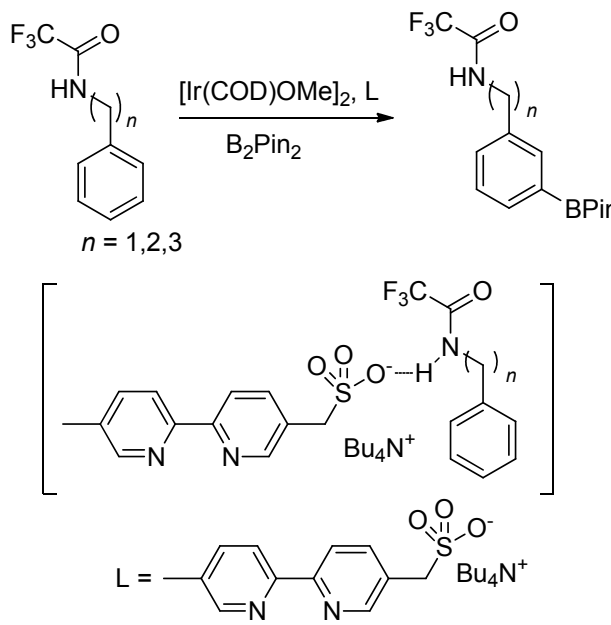

图式 14 氢键作用力促进间位活化

Scheme 14 Hydrogen bond accelerated meta-C-H activation

Chattopadhyay 小组 ${ }^{[64]}$ 通过配体中阳离子与底物 $\pi$
键之间的非共价键作用力实现了苯甲酰胺间位硼化反 应，对各种取代的苯甲酰胺衍生物都以高的产率得到间 位硼化产物(Scheme 14).

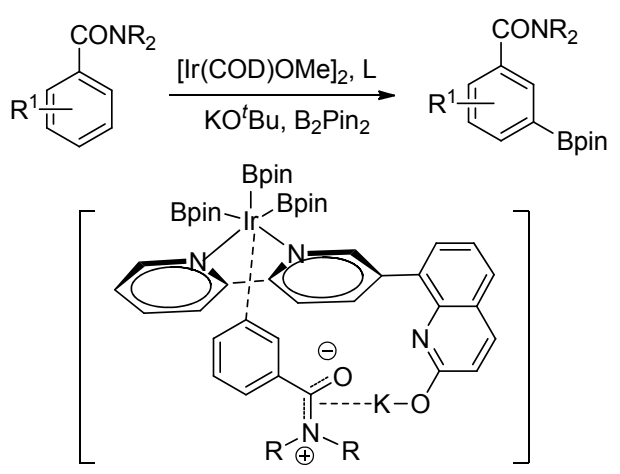

$\mathrm{R}=\mathrm{CH}_{3}, \mathrm{Et},{ }^{\mathrm{t}} \mathrm{Bu},{ }^{i} \mathrm{Pr}$, Hex etc.

$\mathrm{R}^{1}=\mathrm{CH}_{3}, \mathrm{CO}_{2} \mathrm{Me}, \mathrm{C}_{6} \mathrm{H}_{5}, \mathrm{OCH}_{3}, \mathrm{~F}, \mathrm{Cl}, \mathrm{CF}_{3}, \mathrm{CN}$ etc.

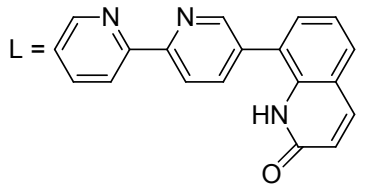

图式 15 阳离子与 $\pi$ 键作用力导向间位活化

Scheme 15 Interaction between $\pi$ bond and cationic accelerated meta-C $-\mathrm{H}$ activation

\section{4 结论与展望}

虽然 U-型模板在间位选择性活化中表现出优越的 性能，但此策略需要设计特定模板，模板以共价键与底 物结合，反应后需借助化学方法脱除模板. 配体次级作 用力导向的间位活化缺点是次级作用力较弱，在较高温 度条件下不易形成，目前催化体系比较单一，都是 Ir 催 化下的硼化反应. 降冰片烯介导碳氢间位活化导向基具 有一定的优势，但是降冰片烯介导间位活化多为芳基化 和烷基化，芳基化和烷基化试剂多为碘试剂. 因此，开 发催化体系多样化的瞬态介导间位活化的未来的发展 方向.

\section{References}

[1] Mkhalid, I.-A.-I.; Barnard, J.-H.; Marder, T.-B.; Murphy, J.-M.; Hartwig, J.-F. Chem. Rev. 2010, 110, 890.

[2] Zhang, Y.-H.; Shi, B.-F.; Yu, J.-Q. J. Am. Chem. Soc. 2009, 131, 5072 .

[3] Hofmann, N.; Ackermann, L. J. Am. Chem. Soc. 2013, 135, 5877.

[4] Madalina, T.-M.; Genov, G.-R.; Phipps, R.-J. Chem. Soc. Rev. 2018, 47,149

[5] Dey, A.; Sinha, S.-K.; Achar, T.-K.; Maiti, D. Angew. Chem., Int Ed. 2019, 58, 2

[6] Yang, J. Org. Biomol. Chem. 2015, 13, 1930.

[7] Chen, Z.-K.; Wang, B.-J.; Zhang, J.-T.; Yu, W.-L.; Liu, Z.-X.; Zhang, Y.-H. Org. Chem. Front. 2015, 2, 1107.

[8] Leow, D.; Li, G.; Mei, T.-S.; Yu, J.-Q. Nature 2012, 486, 518.

[9] Yang, Y.-F.; Cheng, G.-J.; Liu, P.; Leow, D.; Sun, T.-Y.; Chen, P.; Zhang, X.-H.; Yu, J.-Q.; Wu, Y.-D.; Houk, K. N. J. Am. Chem. Soc. 
2014, 136, 344.

[10] Lee, S.; Lee, H.; Tan, K. L. J. Am. Chem. Soc. 2013, 135, 18778.

[11] Yang, G.-Q.; Lindovska, P.; Zhu, D.-J.; Kim, J.; Wang, P.; Tang, R.-Y.; Movassaghi, M.; Yu, J.-Q. J. Am. Chem. Soc. 2014, 136, 10807.

[12] Mi, R.-J.; Sun, J.; Kühn, F.-T.; Zhou, M.-D.; Xu, Z.-Q. Chem. Commun. 2017, 53, 1320.

[13] Mi, R.-J.; Sun, Y.-Z.; Wang, J.-Y.; Sun, J.; Xu, Z.-Q.; Zhou, M.-D. Org. Lett. 2018, 20, 5126.

[14] Cheng, G.-J.; Yang, Y.-F.; Liu, F.; Chen, P.; Sun, T.-Y.; Li, G.; Zhang, X.-H.; HouK, K.-N.; Yu, J.-Q.; Wu, Y.-D. J. Am. Chem. Soc. 2014, 136, 897

[15] Dai, H.-X.; Li, G.; Zhang, X.-G.; Stepan, A.-F.; Yu, J.-Q. J. Am. Chem. Soc. 2013, 135, 7567

[16] Wan, L.; Dastbaravardeh, N.; Li, G.; Yu, J.-Q. J. Am. Chem. Soc. 2013, 135, 18056.

[17] Deng, Y.-Q.; Yu, J.-Q. Angew. Chem., Int. Ed. 2015, 54, 888.

[18] Xu, H.-J.; Lu, Y.; Farmer, M.-E.; Wang, H.-W.; Zhao, D.; Kang, Y.-S.; Sun, W.-Y.; Yu, J.-Q. J. Am. Chem. Soc. 2017, 139, 2200.

[19] Xu, H.-J.; Kang, Y.-S.; Shi, H.; Zhang, P.; Chen, Y.-K.; Zhang, B.; Liu, Z.-Q.; Zhao, J.; Sun, W.-Y.; Yu, J.-Q.; Lu, Y. J. Am. Chem. Soc. 2019, 141, 76 .

[20] Bera, M.; Modak, A.; Patra, T.; Maji, A.; Maiti, D. Org. Lett. 2014, 16,5760 .

[21] Bera, M.; Maji, A.; Sahoo, S.-K.; Maiti, D. Angew. Chem., Int. Ed. 2015, 54, 8515 .

[22] Maji, A.; Bhaskararao, B.; Singha, S.; Sunoj, R.-B.; Maiti, D. Chem. Sci. 2016, 7, 3147.

[23] Modak, A.; Mondal, A.; Watile, R.; Mukherjee, S.; Maiti, D. Chem. Commun. 2016, 52, 13916.

[24] Bera, M.; Agasti, S.; Chowdhury, R.; Mondal, R.; Pal, D.; Maiti, D. Angew. Chem., Int. Ed. 2017, 56, 5272.

[25] Modak, A.; Patra, T.; Chowdhury, R.; Raul, S.; Maiti, D. Organometallics 2017, 36, 2418.

[26] Bera, M.; Sahoo, S.-K.; Maiti, D. ACS Catal. 2016, 6, 3575.

[27] Patra, T.; Watile, R.; Agasti, S.; Naveen, T.; Maiti, D. Chem. Commun. 2016, 52, 2027.

[28] Maity, S.; Hoque, E.; Dhawa, U.; Maiti, D. Chem. Commun. 2016, $52,14003$.

[29] Zhang, L.-L.; Zhao, C.-Y.; Liu, Y.; Xu, J.-C.; Xu, X.-F.; Jin, Z. Angew. Chem., Int. Ed. 2017, 56, 12245.

[30] Tang, R.-Y.; Li, G.; Yu, J.-Q. NATURE 2014, 507, 215.

[31] Li, S.-D.; Ji, H.-F.; Cai, L.; Li, G. Chem. Sci. 2015, 6, 5595.

[32] Li, S.-D.; Cai, L.; Ji, H.-F.; Yang, L.; Li, G. Nat. Commun. 2016, 7, 1.

[33] Fang, L.-Z.; Saint-Denis, T.-G.; Taylor, B.-L.; Ahlquist, S.; Hong, K.; Liu, S.-S.; Han, L.-L.; Houk, K.-N.; Yu, J.-Q. J. Am. Chem. Soc. 2017, 139, 10702.

[34] Yang, L.; Fu, L.; Li, G. Adv. Synth. Catal. 2017, 359, 2235.

[35] Xu, J.-C.; Chen, J.-J.; Gao, F.; Xie, S.-G.; Xu, X. H.; Jin, Z.; Yu, J.-Q. J. Am. Chem. Soc. 2019, 141, 1903.

[36] Wang, B.; Zhou, Y.; Xu, N.-N.; Xu, X.-F.; Xu, X.-H.; Jin, Z. Org. Lett. 2019, 21, 1885.

[37] Chu, L.; Shang, M.; Tanaka, K.; Chen, Q.-H.; Pissarnitski, N.;
Streckfuss, E.; Yu, J.-Q. ACS Cent. Sci. 2015, 1, 394.

[38] Jin, Z.; Chu, L.; Chen, Y.-Q.; Yu, J.-Q. Org. Lett. 2018, $20,425$.

[39] Bag, S.; Jayarajan, R.; Mondal, R.; Maiti, D. Angew. Chem., Int. Ed. 2017, 56, 3182.

[40] Bag, S.; Jayarajan, R.; Dutta, U.; Chowdhury, R.; Mondal, R.; Maiti, D. Angew. Chem., Int. Ed. 2017, 56, 12538.

[41] Jayarajan, R.; Das, J.; Bag, S.; Chowdhury, R.; Maiti, D. Angew. Chem., Int. Ed. 2018, 57, 7659 .

[42] Fang, S.-Q.; Wang, X.-B.; Yin, F.-C.; Cai, P.; Yang, H.-L.; Kong, L.-Y. Org. Lett. 2019, 21, 1841

[43] Dutta, U.; Modak, A.; Bhaskararao, B.; Bera, M.; Bag, S.; Mondal, A.; Lupton, D.-W.; Sunoj, R.-B.; Maiti, D. ACS Catal. 2017, 7, 3162.

[44] Wang, X.-C.; Gong, W.; Fang, L.-Z.; Zhu, R.-Y.; Li, S.-H.; Engle, K.-N.; Yu, J.-Q. Nature 2015, 519, 334.

[45] Shen, P.-X.; Wang, X.-C.; Wang, P.; Zhu, R.-Y.; Yu, J.-Q. J. Am. Chem. Soc. 2015, 137, 11574.

[46] Han, J.; Zhang, L.; Zhu, Y.; Zheng Y.-X.; Chen, X.-L.; Huang, Z.-B.; Shi, D.-Q.; Zhao, Y.-S. Chem. Commun. 2016, 52, 6903.

[47] Dong, Z.; Wang, J.-C.; Dong, G.-B. J. Am. Chem. Soc. 2015, 137, 5887.

[48] Wang, P.; Li, G.-C.; Jain, P.; Farmer, M.-E.; He, J.; Shen, P.-X.; Yu, J.-Q. J. Am. Chem. Soc. 2016, 138, 14092.

[49] Wang, P.; Farmer, M.-E.; Huo, X.; Jain, P.; Shen, P.-X.; Ishoey, M.; Brandner, J.-E.; Wisniewski, S.-R.; Eastgate, M.-D.; Yu, J.-Q. J. Am. Chem. Soc. 2016, 138, 9269.

[50] Li, G.-C.; Wang, P.; Farmer, M.-E.; Yu, J.-Q. Angew. Chem., Int. Ed. 2017, 56, 6874 .

[51] Ding, Q.-P.; Ye, S.-Q.; Cheng, G.-L.; Wang, P.; Farmer, M.-E.; Yu, J.-Q. J. Am. Chem. Soc. 2017, 139, 417.

[52] Wang, P.; Farmer, M.-E.; Yu, J.-Q. Angew. Chem., Int. Ed. 2017, 56, 5125.

[53] Liu, J.-Y.; Ding, Q.-P.; Fang, W.-J.; Wu, W.-H.; Zhang, Y.-G.; Peng, Y.-Y. J. Org. Chem. 2018, 83, 13211.

[54] Cheng, G.-L.; Wang, P.; Yu, J.-Q. Angew. Chem., Int. Ed. 2017, 56, 8183.

[55] Li, Q.-K.; Ferreira, E. M. Chem.-Eur. J. 2017, 23, 11519.

[56] Farmer, M.-E.; Wang, P.; Shi, H.; Yu, J.-Q. ACS Catal. 2018, 8, 7362.

[57] Kuninobu, Y.; Ida, H.; Nishi, M.; Kanai, M. Nat. Chem. 2015, 7, 712.

[58] Lu, X.; Yoshigoe, Y.; Ida, H.; Nishi, M.; Kanai, M.; Kuninobu, Y. ACS Catal. 2019, 9, 1705.

[59] Unnikrishnan, A.; Sunoj, R.-B. Chem. Sci. 2019, 10, 3826.

[60] Yang, L.-C.; Uemura, N.; Nakao, Y. J. Am. Chem. Soc. 2019, 141, 7912.

[61] Bisht, R.; Chattopadhyay, B. J. Am. Chem. Soc. 2016, 138, 84

[62] Davis; H.-J.; Mihai, M.-T.; Phipps, R.-J. J. Am. Chem. Soc. 2016, $138,12759$.

[63] Davis, H.-J.; Genov, G.-R.; Phipps, R.-J. .Angew. Chem., Int. Ed. 2017, 56, 13351 .

[64] Bisht, R.; Hoque, M.-E.; Chattopadhyay, B. Angew. Chem., Int. Ed. 2018, 57,15762 . 